\title{
Semi-Semantic AnNotation: A Guideline for the URDU.KON-TB Treebank POS ANNOTATION
}

\author{
Qaiser ABBAS \\ University of Sargodha, Pakistan \\ qaiser.abbas@uos.edu.pk
}

\begin{abstract}
This work elaborates the semi-semantic part of speech annotation guidelines for the URDU.KON-TB treebank: an annotated corpus. A hierarchical annotation scheme was designed to label the part of speech and then applied on the corpus. This raw corpus was collected from the Urdu Wikipedia and the Jang newspaper and then annotated with the proposed semi-semantic part of speech labels. The corpus contains text of local \& international news, social stories, sports, culture, finance, religion, traveling, etc. This exercise finally contributed a part of speech annotation to the URDU.KON-TB treebank. Twenty-two main part of speech categories are divided into subcategories, which conclude the morphological, and semantical information encoded in it. This article reports the annotation guidelines in major; however, it also briefs the development of the URDU.KON-TB treebank, which includes the raw corpus collection, designing \& employment of annotation scheme and finally, its statistical evaluation and results. The guidelines presented will be useful for linguistic community to annotate sentences not only for the national language Urdu but for the other indigenous languages like Punjab, Sindhi, Pashto, etc. as well.
\end{abstract}

Keywords: semi-semantic part of speech; rich information; deep learning; parsing aid; linguistically motivated annotation; humanistic annotation

\section{Povzetek}

Rezultat tega dela so navodila za označevanje polsemantičnih besednih vrst v drevesnici URDU.KON-TB. Hierarhična označevalna shema je bila oblikovana z namenom, da razvrsti besedne vrste in jih kot take uporabi na korpusih. Tokratni koprus, ki je sestavljen iz strani Urdu Wikipedie in časopisa Jang, je bil označen s predlaganimi polsemantičnimi besednimi vrstami. Korpus vsebuje tekste lokalnih in mednarodnih novic, zgodbe s socialno temo, šport, kulturo, finance, vero, potovanja in druge teme. Uspešen poskusa označevanja je nadgradil drevesnico URDU.KON-TB. Dvaindvajset osnovnih besednih vrst je razdeljenih v podkategorije z morfološkimi in semantičnimi informacijami. Članek podaja jasne osnovne smernice označevanja. Hkrati ponuja kratek pregled razvoja drevesnice URDU.KON-TB, ki vsebuje zbirke surovih korpusov, oblikovanje in uporabo shem za označevanje ter nenazadnje tudi statistično oceno in rezultate. Predlagana navodila za označevanje so namenjena jezikovnim skupnostim, ki označujejo stavke tako v državnem jeziku Urdu kot tudi v drugih jezikih, kot so Punjab, Sindhi in drugih.

Ključne besede: polsemantična besedna vrsta; številne informacije; globoko učenje; pomoč pri razvrščanju; jezikoslovno utemeljeno označevanje; humanistično označevanje 


\section{Introduction}

A treebank or a parsed corpus is a text corpus of sentences annotated with a syntactic structure. Today, many natural language processing (NLP) and machine learning (ML) applications rely on treebanks. Treebanks are heavily used in corpus linguistics for investigating syntactic phenomena or in computational linguistics for training or testing parsers. The sentences in the treebank should be annotated according to a devised annotation scheme as presented in Figure 1 to 4 in our case. Annotation schemes can include the labeling to represent morphological forms, word classes, syntactic structures, semantics, grammatical arguments, co-references, etc. So, the corpus annotation is simply the addition of interpretative linguistic information to a corpus (Leech, 2005).

Annotation scheme that was used to develop the URDU.KON-TB treebank (Abbas, 2012, 2014a, 2014b) for the South Asian language Urdu is presented next with complete guidelines in Section 2. This annotation is actually encoded with the morphology, POS, syntactical and functional information including the handling of displaced constituents, empty categories, antecedents and anaphors, etc., but here only the case of semi-semantic part of speech (SSP) is discussed concisely. Such development of an annotation scheme is the fundamental step to build a treebank, for which the computational linguists then devise the annotation guidelines (Section 2), which is a compulsory part to build, and without which the annotation scheme has no worth at all. Annotation structure for the development of the URDU.KON-TB treebank has the combination of the PS (Phrase Structure) and the HDS (Hyper Dependency Structure) annotation detailed in Section 3.2. Annotation issues emerged during the development (Abbas, 2012) have been corrected in (Abbas, 2014a \& 2014b) and the annotation guidelines presented in Section 2 is the most updated version. The corpus containing 1400 sentences $^{1}$ (discussed in Section 3.1) for the development of the URDU.KON-TB treebank was collected from the Urdu Wikipedia ${ }^{2}$ and the Urdu Jang newspaper. ${ }^{3}$

\footnotetext{
${ }^{1}$ The size has been augmented recently to 2000 sentences by a student in her master's thesis "Annexing Treebank and the Urdu Parser"

${ }^{2}$ https://ur.wikipedia.org/wiki/ول_فٔ صـ

${ }^{3}$ http://jang.com.pk/index.html
} 


\begin{tabular}{|c|}
\hline ADJ (Adjective) \\
\hline .DEG (Degree) \\
\hline ECO (Echo) \\
\hline .MNR (Manner) \\
\hline .SPT (Spatial) \\
\hline .TMP (Temporal) \\
\hline ADV (Adverb) \\
\hline .DEG (Degree) \\
\hline MNR (Manner) \\
\hline NEG (Negative) \\
\hline SPT (Spatial) \\
\hline TMP (Temporal) \\
\hline .REL (Relative) \\
\hline C (Conjunction) \\
\hline .CAUS (Causative) \\
\hline CONS (Concessive) \\
\hline CORD (Coordinative) \\
\hline CORR (Co-relative) \\
\hline SBORD (Subordinating) \\
\hline .COND (Conditional) \\
\hline CM (Case Marker) \\
\hline DATE (Date) \\
\hline . D (Day) \\
\hline M (Month) \\
\hline.$Y($ Year) \\
\hline HADEES (Hadees) \\
\hline INT (Interjection) \\
\hline M (Marker) \\
\hline P (Phrase) \\
\hline.$S$ (Sentence) \\
\hline $\mathbf{N}$ (Noun) \\
\hline ADJ (Adjective) \\
\hline MNR (Manner) \\
\hline .REP (Repeat) \\
\hline PROP (Proper) \\
\hline .SPT (Spatial) \\
\hline .TMP (Temporal) \\
\hline .REP (Repeat) \\
\hline SPT (Spatial) \\
\hline .REP (Repeat) \\
\hline TMP (Temporal) \\
\hline .REP (Repeat) \\
\hline P (Pronoun) \\
\hline .DEM (Demonstrative) \\
\hline INDF (Indefinite) \\
\hline PERS (Personal) \\
\hline POSS (Possessive) \\
\hline .REF (Reflexive) \\
\hline .REP (Repeat) \\
\hline REF (Reflexive) \\
\hline
\end{tabular}

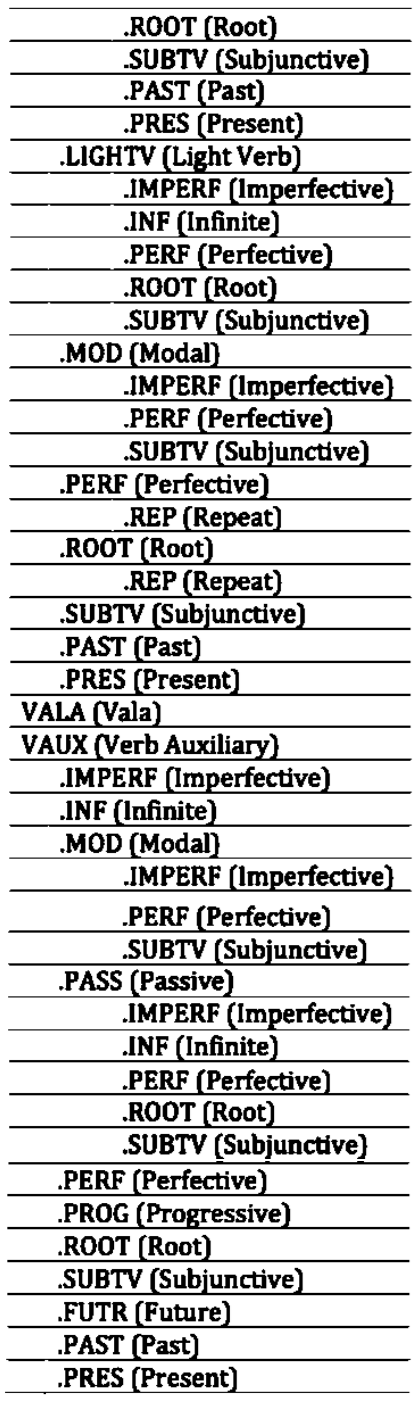

Figure 1: A detailed version of the SSP tagset for the URDU.KON-TB treebank

The reliability of the treebank annotation or the annotation guidelines can be measured by calculating the agreement or the homogeneity among the annotators of the treebank. The reliability evaluation is a complex task for the treebank that contains rich information, but it is an essential part to play for the production of a quality treebank, so that the annotation can be readable. The annotation evaluation (Abbas, 
$2014 a \& 2014 b)$ resolved most of our annotation issues except few. The guidelines of the URDU.KON-TB treebank are evaluated using a statistical measure known as the Krippendorf's a coefficient (Krippendorf, 2004). This can be used to evaluate the interannotator agreement (IAA). Randomly selected one hundred (100) sentences from the URDU.KON-TB treebank were given to five trained annotators for annotation. The annotated sentences then evaluated using the Krippendorf's $\alpha$ co-efficient. The $\alpha$ values of the IAA obtained for the part of speech (SSP) annotation is 0.964. The annotation guidelines were revised during and after this annotation evaluation. A little detailed presentation of evaluation is given in Section 4.

Section 2 describes the up to date annotation guidelines revised after the annotation evaluation (Abbas, 2014a \& 2014b). Guidelines regarding the SSP annotation are detailed here in this article for easiness and simplicity along with their respective examples. To remain on track, the annotation tags are discussed according to the order of the SSP tags given in Figure 1. The discussion of the annotation guidelines is kept concise.

\begin{tabular}{l}
\hline ADJ (Adjective) \\
\hline ADV (Adverb) \\
\hline C (Conjunction) \\
\hline CM (Case marker) \\
\hline DATE (Date) \\
\hline HADEES (Narration of prophets deeds) \\
\hline INT (Interjection) \\
\hline M (Marker) \\
\hline $\mathrm{N}$ (Noun) \\
\hline P (Pronoun) \\
\hline POSTP (Postposition)
\end{tabular}

\begin{tabular}{l}
\hline PRAY (Specific statements of prayers) \\
\hline PREP (Preposition) \\
\hline PT (Particle) \\
\hline Q (Quantifier) \\
\hline QW (Question word) \\
\hline SYM (Symbol) \\
\hline TTL (Title) \\
\hline U (Unit) \\
\hline V (Verb) \\
\hline VALA (Special Word Vala) \\
\hline VAUX (Verb auxiliary) \\
\hline
\end{tabular}

Figure 2: The main POS-tag categories for the URDU.KON-TB treebank

\begin{tabular}{l}
\hline PROG (Progressive form) \\
\hline PASS (Passive form) \\
\hline FUTR (Future tense) \\
\hline PAST (Past tense) \\
\hline PRES (Present tense) \\
\hline
\end{tabular}

\begin{tabular}{l}
\hline PROG (Progressive form) \\
\hline PASS (Passive form) \\
\hline FUTR (Future tense) \\
\hline PAST (Past tense) \\
\hline PRES (Present tense) \\
\hline
\end{tabular}

Figure 3: Morphological tag set to annotate subcategories of verbs and auxiliaries

\begin{tabular}{|c|c|}
\hline \multicolumn{2}{|c|}{ Semantic labels } \\
\hline CMP (Comparative) & POSS (Possessive) \\
\hline INST (Instrumental) & SPT (Spatial) \\
\hline MNR (Manner) & TMP (Temporal) \\
\hline
\end{tabular}

Figure 4: Functional tag set for the URDU.KON-TB treebank 


\section{Semi-Semantic POS (SSP) Annotation}

The term semi-semantic (partly or partially semantic) is used with the POS because some tags are encoded with semantics but not all e.g. N.SPT (a spatial noun) tag for a word house, ADJ.TMP (a temporal adjective) tag for a word previous in previous year, etc. There are twenty two (22) main POS tag categories, which are displayed in Figure 2. The description of the tags is given in the respective cells of the figure. These main categories are further divided into morphological and semantical subcategories according to the Figures 3 and 4, respectively. The final and detailed version of the SSP tag set is given in Figure 1. The dot "." is used to add the morphological or semantical features to the main category e.g. in V.PERF, a verb $V$ is the main POS category like nouns, adjectives, etc., which has a perfective PERF morphology. The description of each category is as follows. It is to be noted that the Urdu script is written from right to left in coming examples. The row beneath the Urdu script is the transliteration of the sentence as proposed in Malik et al. (2010). Similarly, the row beneath the transliteration of the sentence contains the translated-word/POS-tag pair according to the SSP tag set given in Figure 1. At the end in examples next, a complete English translation of the Urdu sentence is presented. The complete guideline is going to be presented next, however, its employment procedure on the raw corpus to form the URDU.KON-TB treebank can be seen in Section 3.3. It is advised to skip this Section 2 for later reading and go to Section 3 to understand the flow of the article as this section concludes the deep design of the annotation guidelines.

\subsection{Adjectives}

Adjectives are used to modify a noun or pronoun (Aarts et al., 2014; Matthews, 2007; Miller et al., 1990; Stevenson, 2010). The first main category in Figure 1 is about ADJ (Adjective), which is divided into further five sub categories of tags included DEG (Degree), ECO (Echo), MNR (Manner), SPT (Spatial) and TMP (Temporal). The relevant POS annotations are provided in examples 1. Example 1(a) is the case of main POS category ADJ of adjective. There are some words like tar 'more' and tarln 'most', which truly act as a degree adjective and not as degree adverb but there are some words which can play the role of a degree adverb or a degree adjective e.g. ziyAdah 'more/much', bohat 'more/much', etc, (Schmidt, 2013). Example 1(b) is the case of degree adjective ADJ.DEG. Example 1(c) is the case of reduplication ${ }^{4}$ (Abbi, 1992; Boegel et al., 2007). Reduplication has two versions. First is discussed in a footnote below, while the other is the repetition of the original word e.g. SAtH SAtH 'with/alongwith'. These two versions are named as echo reduplication and full word reduplication by Boegel et al. (2007), which are refurbished in our annotation as ECO (echo

\footnotetext{
${ }^{4}$ In Urdu like other South Asian languages, the reduplication of a content word is frequent. Its effect is only to strengthen the proceeding word or to expand the specific idea of a proceeding word into a general form e.g. KAm THIk-THAk karnA 'Do the work right' or kOI kapRE-vapRE dE dO 'Give me the clothes or something like those'
} 
reduplication) and REP (full word reduplication/repetition) respectively. The echo words normally start with the letters $S$ or $v$ or $m$. The next examples from 1(d) to 1 (f) are the cases of adjectives, which have the meaning of MNR, TMP and a SPT respectively. The addition of this MNR, TMP and SPT after the POS tag ADJ represents the semantics.

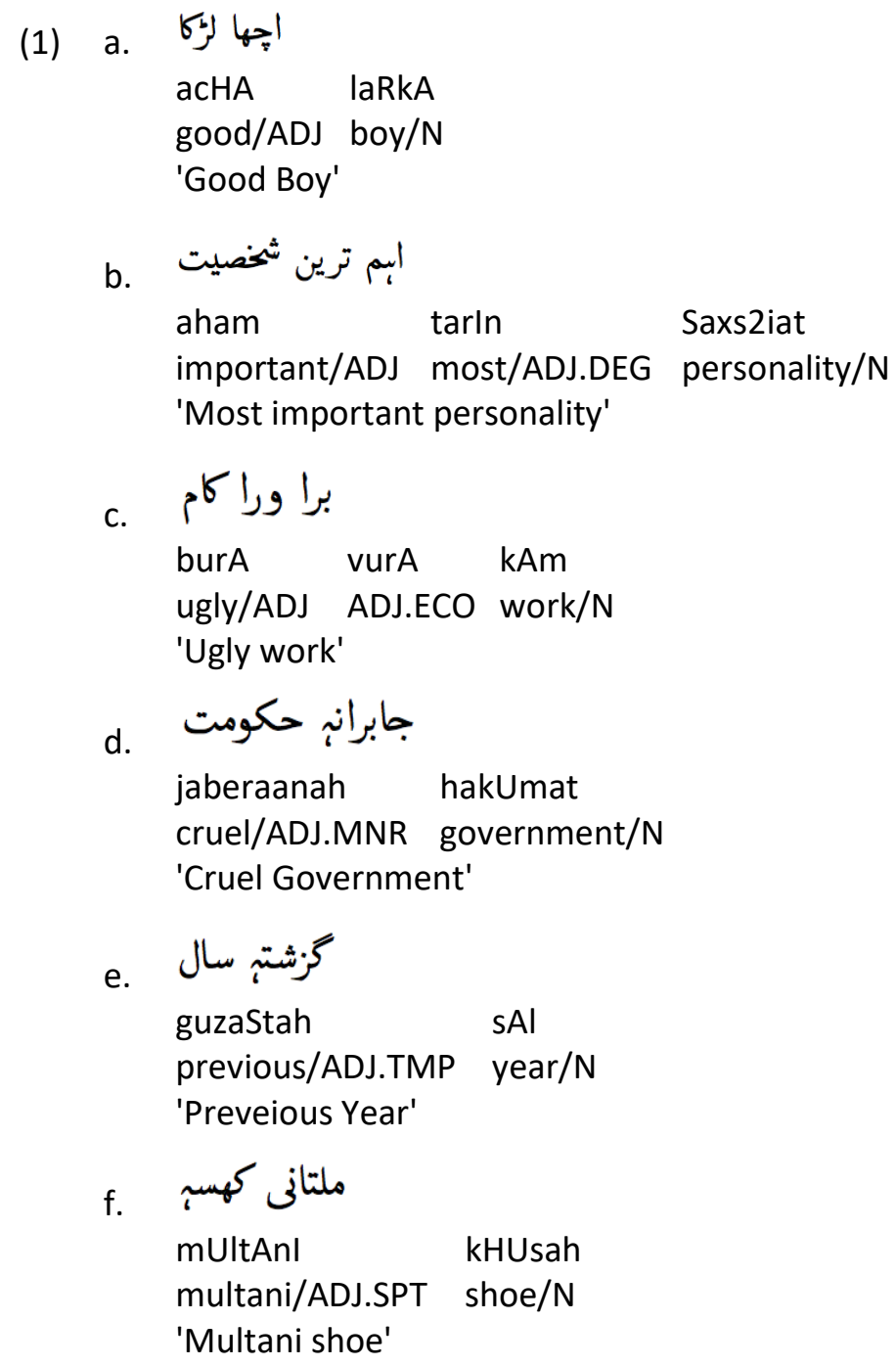

\subsection{Adverbs}

Adverbs can modify verbs, adjectives or other adverbs. They can also modify phrases, clauses and sentences (Aarts et al., 2014; Matthews, 2007; Miller et al., 1990; Stevenson, 2010). Adverbs are mostly used as a qualifier of the verbs but they can also be used independently. They are subcategorized into six forms presented in Figure 1. The annotations are given in example 2 . The main category of adverbs ADV is annotated in 2(a), which is further divided into five subcategories DEG (degree), MNR (manner), 
NEG (negative), SPT (spatial) and TMP (temporal). The final TMP has another subcategory REL for relative temporal adverb. In 2(b), an adverb bohat 'very' is used before an adjective $a c H I$ 'good' and it is highlighting the adjective at a certain degree, hence annotated as ADV.DEG. In 2(c), biltartlb 'respectively' behaves as an adverb and advocates a manner of order as ADV.MNR. The word nah 'not' is a negative adverb negating the action in 2(d) and it is annotated with ADV.NEG relatively. A word sAmnE 'front/before' is a spatial adverb and annotated as ADV.SPT in 2(e). The case of temporal adverb is displayed in 2(f), where a word $a b$ 'now' is annotated as ADV.TMP. This temporal adverb is divided into another hierarchy named relative-temporal adverb, which can be seen in the last example 2(g). A word jab 'when' is given a POS tag as ADV.TMP.REL as follows.
a. تقريبا سارى دنيا ميس
taqriban sArl dunlyA mEN
almost/ADV whole/Q world/N.SPT in/CM

'Almost in the whole world'

b. بهت إجهى لرّكى

bohat acHI laRkl

very/ADV.DEG good/ADJ girl/N

'Very good girl'

c. تعداد بالترتيب ه اور \& تهى

$\begin{array}{llll}\text { te2dAd } & \text { biltartlb } & 5 & \text { aor } \\ \text { quantity/N } & \text { respectively/ADV.MNR } & \text { 5/Q.CARD } & \text { and/C.CORD } \\ 6 & \text { tHI } & & \\ \text { 6/Q.CARD } & \text { was/V.COP.PAST } & & \end{array}$

'The quantity was 5 and 6 respectively'

d. عارت مكمل ن هو سكى

e2emArat mukammal nah ho sakl building/N complete/ADJ not/ADV.NEG be/V.LIGHT.ROOT could/V.MOD.PERF 'The building could not be completed'

e. تفيلات سامنح آئي

$\begin{array}{llll}\text { tafs2IIAt } & \text { sAmnE } & \text { AyIN } & \text { gl } \\ \text { details/N } & \text { front/ADV.SPT } & \text { come/V.SUBTV } & \text { will/VAUX.FUTR }\end{array}$

'The details will come out'

f. اب ديكهنا يح بـ

ab dEkHnA yE hE now/ADV.TMP to-see/V.INF this/P.PERS be/V.COP.PRES

'Now, this is to be seen' 
g.

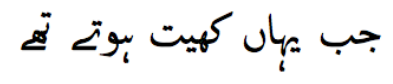

jab $\quad$ yahAN
when/ADV.TMP.REL here/ADV.SPT
crop-field/N.SPT
hotE thE IMPERF was/VAUX.PAST
'When, there were crop fields here'

\subsection{Conjunctions}

Conjunctions are used to connect words, phrases, clauses or sentences (Aarts et al., 2014; Matthews, 2007; Miller et al., 1990; Stevenson, 2010). The main category of conjunction $\mathrm{C}$ is divided into five subcategories e.g., CAUS (causative), CONS (concessive), CORD (coordinative), CORR (correlative) and SBORD (subordinating). The last subcategory has another division of COND to represent conditional subordinate conjunction. The annotation of all divisions is presented in example 3 . Words like cUnkEh 'since, because', cUnAcEh 'so, therefore', kIUnkEh 'because' are candidates for a causative conjunction in a clause. An example of causative conjunction is depicted in Example 3(a). The POS annotation examples of CONS and CORD are given in 3(b) and $3(\mathrm{c})$, respectively. The word agarcEh 'although' is acting as a concessive conjunction in the beginning of sentence in 3(b), while the other word aor 'and' is a coordinating conjunction in 3(c). The word nah 'not/neither' as a correlative conjunction is presented in 3(d), in which it is annotated with C.CORR tag. The subordinating conjunction C.SBORD is annotated in 3(e) for a word kEh 'that'. The C.SBORD is divided into another subcategory proposed as COND for conditional subordinating conjunction. Its annotation for a word agar 'if' is presented in 3(f).

a.

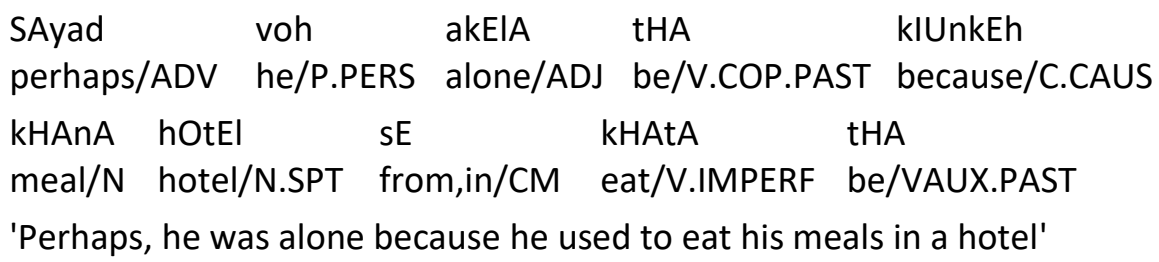

b. agarcEh Adml kam tHE magar men/N less/ADJ were/V.COP.PAST although/C.CONS but/C.CORD voh pHir bHI jlt gaye they/P.PERS then/ADV too/PT.INTF won/V.ROOT V.LIGHTV.PERF

'Although the men were less but they had won either'
c. te2dAd biltartlb 5 aor quantity/N respectively/ADV.MNR 5/Q.CARD and/C.CORD $6 \quad \mathrm{tHI}$ 6/Q.CARD was/V.COP.PAST

'The quantity was 5 and 6 respectively' 
d. nah to tUm kHEIE nah

neither/C.CORR PT.EMP you/P.PERS played/V.PERF nor/C.CORR

hI kHEInE diyA

PT.INTF play/V.INF gave/V.LIGHTV.PERF

'Neither you played yourself nor you allowed to play others'

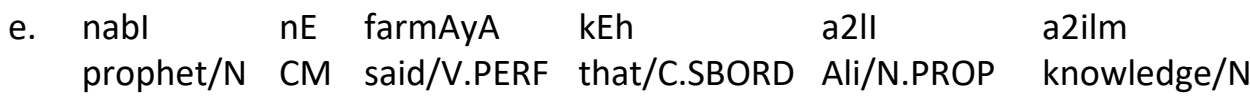

kA darvazah hEN

of/CM door/N.SPT is/V.COP.PRES

'The prophet stated that Ali is the door to knowledge'

f. agar $y$ Eh mErA mAl hOtA

if/C.SBORD.COND it/P.PERS my/P.POSS property/N be/V.IMPERF

tO $\quad$ mEN xarc kartA

then/PT.RESULT I/P.PERS spend/V.ROOT do/V.LIGHTV.IMPERF

'If it would be my property then I will spend it'

\subsection{Case markers}

Case markers (CM) distinguish the grammatical functions of words, phrases, clauses, or sentences (Aarts et al., 2014; Matthews, 2007; Miller et al., 1990; Stevenson, 2010). Urdu case markers are syntactic clitics (Butt and Sadler, 2003) and divided into different forms by Butt and King (2004) e.g., ergative, accusative, dative, possessive, etc. All Urdu case markers are annotated with a simple CM tag at POS level. Four annotated examples can be seen in 3(a), 3(e) and 2(a) for instrumental case marker $s E$ 'from', ergative case marker $n E$, possessive case marker $k A / k l / k E$ 'of' and spatial case marker $m E N / p a r / t a k$ 'in/on/at'. The different forms of case markers play an important role in identification of argument structure like subject, object, etc. The effect of different forms and their related argument structure is discussed in Abbas (2014b).

\subsection{Date}

The DATE tag is used to represent dates of a month e.g. 14, 2, 31, etc. This tag is divided into three subcategories, which includes DATE.D, DATE.M and DATE.Y. Annotated examples can be seen in 4 . The days of a week, month name and a year number are represented by DATE.D, DATE.M and DATE.Y, respectively.
(4) aetvAr
16
mayl
2004
$\mathrm{kO}$
sunday/DATE.D 16/DATE
May/DATE.M 2004/DATE.Y on/CM

'On Sunday, 16 May 2004' 


\subsection{Hadees}

The Hadees is a report of deeds and saying of the prophet Muhammad (PBUH). These are tagged as HADEES in the URDU.KON-TB treebank. The Ahadees (plural of Hadees) in Arabic script in Urdu text are tagged only with this tag HADEES. The translated form of Ahadees in Urdu is annotated in a normal way. An example is depicted in 5 as follows. The Hadees with double quotes in the following sentence is in Arabic and hence tagged as HADEES.

(5) rasUl nE kahA " h2UsyEno-minnl-va-anA-min-al-h2UsyEn " prophet/N CM said/V.PERF M.P HADEES M.P

'The prophet said, "Hussain is from me and I am from Hussain"'

\subsection{Interjections}

Interjections are the words or phrases used to exclaim, protest or command in a sentence. These are annotated with a tag INT. The example can be seen in 6 as follows.

(6) oE kHAnA kHAO

OE/INT food/N eat/V.SUBTV

'OE! eat the food'

\subsection{Markers}

The markers are used to identify the boundary of phrases, clauses, or sentences as marked by punctuation. The markers are divided into two subcategories e.g. phrase markers (M.P) and sentence markers (M.S). The punctuation within the sentence like single quotes, double quotes, colon, comma, etc., are annotated with M.P, however the boundary of the sentence like full stop and question mark is annotated with M.S. The annotated example can be seen in 7 as follows. The comma and period is marked by M.P and M.S respectively.

(7) in mEN bHakar $\quad$, laylah
these/P.PERS in/CM
aOr Bhakkar/N.PROP.SPT comma/M.P
and/C.COyyah/N.PROP.SPT
'Bhakkar, Layyah and Lodhran are included in these'

\subsection{Nouns}

The main noun tag $\mathrm{N}$ is divided into six subcategories, which includes adjectival noun (N.ADJ), noun having a manner (N.MNR), proper noun (N.PROP), repeated noun 
(N.REP) ${ }^{5}$, spatial noun (N.SPT) and temporal noun (N.TMP). The words cHotE 'younger' and baRE 'elder' are representing people having some property of young age and old age in 8(a), hence both are annotated with N.ADJ. In 8(b), the word t2arah2 'way, like, type' is first annotated with N.MNR but when the same word is repeated next then it gives the meaning of 'different types' and its repetition is annotated simply with N.MNR.REP. In 8(c), a subcategory N.PROP is annotated for a person name marlyam 'Maryam'. This subcategory is divided into two subcategories spatial and temporal, which are annotated as N.PROP.SPT and N.PROP.TMP for panjAb 'Punjab' and a2ld-ulfit2r 'Eid festival', respectively. A common noun $\mathrm{N}$ is annotated in $8(\mathrm{~b})$ for a word takllfEN 'hardships'. There are some special common nouns, which can be repeated e.g. kOrl kOrl 'single penny'. When some noun is usually repeated then N.REP tag is used. So, this .REP along with the respective POS tag can be used to represent the presence of a repeated word. The annotation of N.SPT and N.TMP can be seen in 8(c) for iz3/Aa2 'districts' and din 'day'. In both the subcategories, the repetition is possible for which the addition of REP with dot "." can be used accordingly.
a. cHOtE baRE
sab
xUS
younger/N.ADJ elder/N.ADJ
all/Q.ADJ happy/ADJ
hOtE
hEN
become/V.COP.IMPERF be/VAUX.PRES
'Younger and elder all become happy'

b. UnhEN

t2arah2 t2arah2

$\mathrm{kl}$

taklIfEN

they/P.PERS

type/N.MNR

type/N.MNR.REP

of/CM

hardships/N

$\begin{array}{lll}\text { dl } & \text { jAnE } & \text { lagIN } \\ \text { give/V.PERF } & \text { go/VAUX.PASS.INF } & \text { start/VAUX.SUBTV }\end{array}$

'They were given hardships of different types'

c. marlyam

panjab

$\mathrm{kE} \quad \mathrm{ba2z}$

iz3IAa2

Maryam/N.PROP Punjab/N.PROP.SPT of/CM some/Q districts/N.SPT

mEN a2ld-ul-fit2r $\mathrm{kE}$ din gayl

into/CM Eid-ul-Fitr/N.PROP.TMP of/CM day/N.TMP went/V.PERF

'Maryam went into some districts of Punjab on the day of Eid-ul-Fitr'

\subsection{Pronouns}

The main category of pronoun $P$ is divided into six subcategories P.DEM (demonstrative pronoun), P.INDF (indefinite pronoun), P.PERS (personal pronoun), P.POSS (possessive pronoun), P.REF (reflexive pronoun) and P.REL (relative pronoun). The first two subcategories P.DEM and P.INDF are annotated in 9(a) for words yeh 'this' and $k O I$ 'any' respectively. The difference between P.PERS and P.DEM is this that when P.PERS refers to some person, place or thing, then this P.PERS behaves as a P.DEM like

\footnotetext{
${ }^{5}$ It lies in the category of full word reduplication as discussed in Section 2.1
} 
in 9(a). The 3rd and 4th category P.PERS and P.POSS are annotated in 9(b) for words $m E N$ 'I' and tumhArA 'your' respectively. P.POSS is further divided into P.POSS.REF, which is annotated for a word apnA 'own' in the same sentence. The repeated subcategory can be annotated after addition of .REP at the end. The fifth and sixth subcategory P.REF and P.REL are annotated in 9(c) for words Apas 'themselves' and jO 'which' respectively. The subcategory P.REL is further divided into P.REL.DEM and P.REL.PERS. These are annotated in 9(d) for words $\mathrm{jO} \underline{\mathrm{kUcH}}$ 'what ever' and jls 'who' respectively.

(9) a. yeh meh2kama kOl kAm nahl kartA this/P.DEM department/N any/P.INDF work/N not/ADV.NEG do/V.IMPERF 'This department does not do any work'

b. MEN tumhArA apnA bHAI hUN I/P.PERS your/P.POSS own/P.POSS.REF brother/N be/V.COP.SUBTV 'I am your own brother'

c. jO Apas mEN moh2abat kl

which/P.REL themselves/P.REF among/CM love/N of/CM mis2Al hE example/N be/V.COP.PRES

'Which is an example of love among themselves'

d. jls $\mathrm{kO}$ jO $\mathrm{kUcH}$ mile who/P.REL.PERS CM what/P.REL.DEM ever/P.INDF find/V.PERF UTHA IEnA CAhIE pick/V.PERF take/V.LIGHTV.INF should/VAUX.MOD.PERF 'Who finds what ever, should pick it up'

\subsection{Postpositions}

The postpositions are placed after a word to which it is grammatically related e.g. $s A t H$ 'with' is a POSTP (postposition) in a postpositional phrase Us kE sAtH 'with him'. The postpositions are divided into six subcategories hierarchically as displayed in Figure 1. These include POSTP.CMP (comparative postposition), POSTP.MNR (postposition having a manner) ${ }^{6}$, POSTP.POSS (possessive postposition), POSTP.REP (repetitive postposition), POST.SPT (spatial postposition) and POSTP.TMP (temporal postposition). The first two subcategories are annotated in 10(a) for postpositions $s E$ 'than' and t2arah2 'like' respectively. In $10(\mathrm{~b})$, the third and fourth subcategories are annotated for postpositions $p A s$ 'have/has' and $s A t H$ 'with' respectively. The last two

\footnotetext{
${ }^{6}$ The prepositions are divided into basic manner, manner by comparison and manner with a reference point by Saint-Dizier (2008) but I applied only manner in general to all related prepositions and postpositions for Urdu.
} 
subcategories are annotated in 10(c) for postpositions qarlb 'near' and ba2d 'after' respectively.

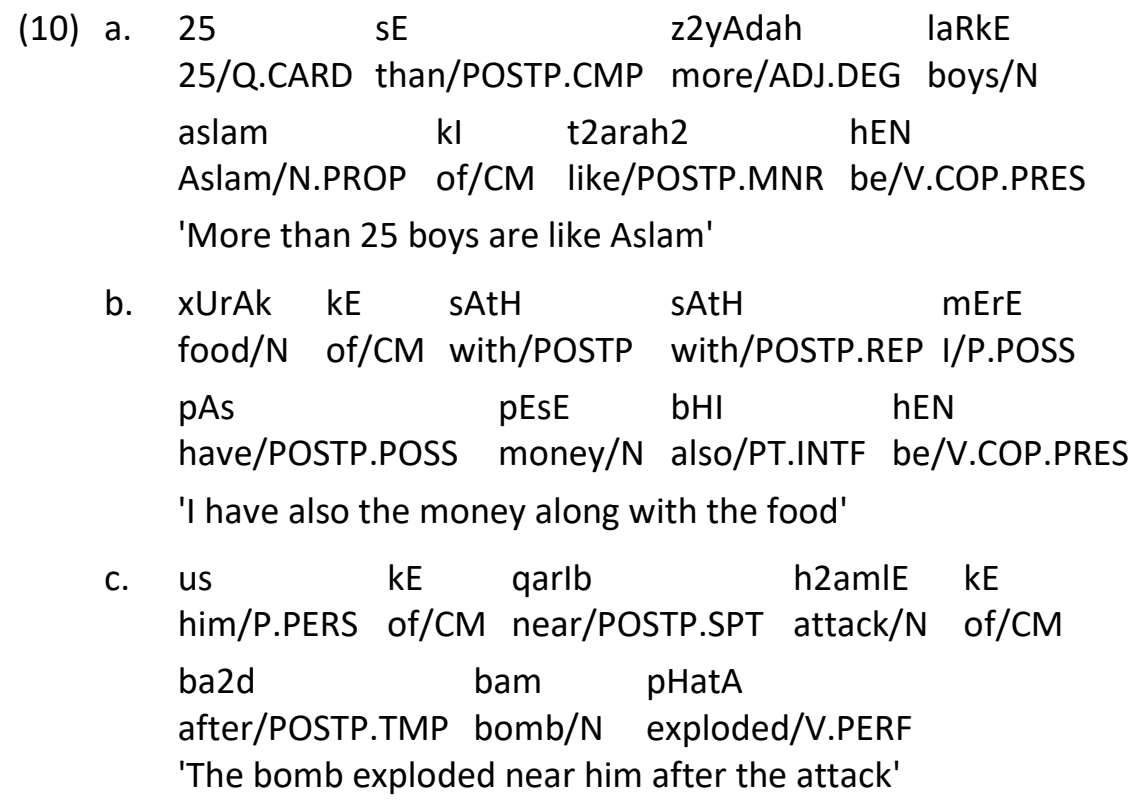

\subsection{Pray}

The PRAY tag is used to annotate all types of prayers normally used in religious literature after the name of prophets, caliphs, and the righteous religious personalities e.g. the alEh salAm 'peace be upon him' is annotated with PRAY after the name of Jesus in 11(a) along with the other example as follows.
(11)
a. h2az3rat a2lsA alEh-salAm allah
h2az3rat/TTL.REG Jesus/N.PROP AS/PRAY Allah/N.PROP
kE Ek a2z4Im nabl hEN
of/CM a/Q.CARD great/ADJ prophet/N be/V.COP.PRES
'Jesus (peach be upon him) is a great prophet of God'
b. h2az3rat mUhammad s3al-lalAhO-a2laehE-va-AlEhl-vasalam nE
TTL.REG Muhammad/N.PROP SAAWW/PRAY CM
h2az3rat a2ll
KO apnA
bHAl banAyA
TTL.REG Ali/N.PROP CM his/P.POSS.REF brother/N made/V.PERF
'Muhammad (peach be upon him and his descendant) made Ali his brother'

\subsection{Prepositions}

The prepositions are placed before a word to which it is grammatically related e.g., $b E$ 'without' is a PREP (preposition) in a prepositional phrase $b E m U h A r$ Sutar 'a camel without a hook). Prepositions are divided into three subcategories hierarchically as 
displayed in Figure 1. These include PREP.MNR (preposition having a manner), PRET.SPT (spatial preposition) and PREP.TMP (temporal preposition). The first two subcategories are annotated in 12(a) for prepositions bat2Or 'as' and andrUnE 'in' respectively. The last subcategory is annotated in 12 (b) for prepositions dOrAnE 'during'.

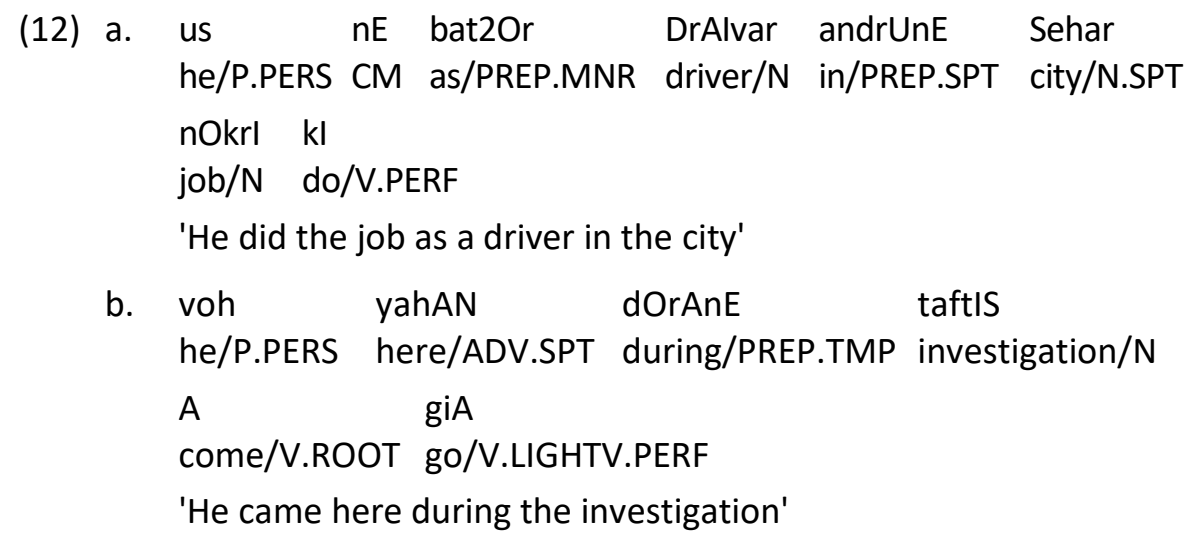

\subsection{Particles}

The particles can appear after a word. These are divided into four subcategories, which include PT.ADJ (adjectival particles), PT.EMP (emphatic particles), PT.INTF (Intensifying particles) and PT.RESULT (resultant particles). All the subcategories are non-inflected except the PT.ADJ, which appears after adjective, adverb, noun or pronoun and agrees with the qualifier. The first and third subcategories are annotated in 13(a) for the particles $s A$ 'like' and $b H I$ 'too'. The annotation of PT.EMP is displayed in 13 (b) for a word $t O$. The contrastive meaning is understood by default due to usage of PT.EMP in this sentence. In 13(c), the annotation of PT.RESULT is given for a word tO 'then'.

$$
\begin{aligned}
& \text { a. voh Ek nAxUSgavAr SA bandah } \\
& \text { he/P.PERS a/Q.CARD unpleasant/ADJ like/PT.ADJ man/N } \\
& \text { bHI } \quad h E \\
& \text { too/PT.INTF be/V.COP.PRES }
\end{aligned}
$$

'He is like an unpleasant man too'

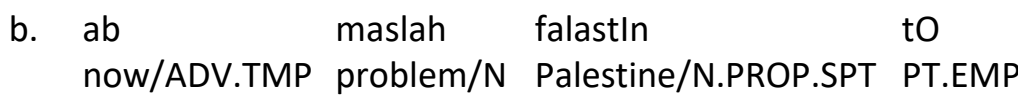

$\begin{array}{lll}\text { h2al } & \text { hO } & \text { gA } \\ \text { resolve/N } & \text { be/V.LIGHT.ROOT } & \text { will/VAUX.FUTR }\end{array}$

'Now, the problem of Palestine will resolve (contrast: "the other problems will not" due to 'tO' effect)' 


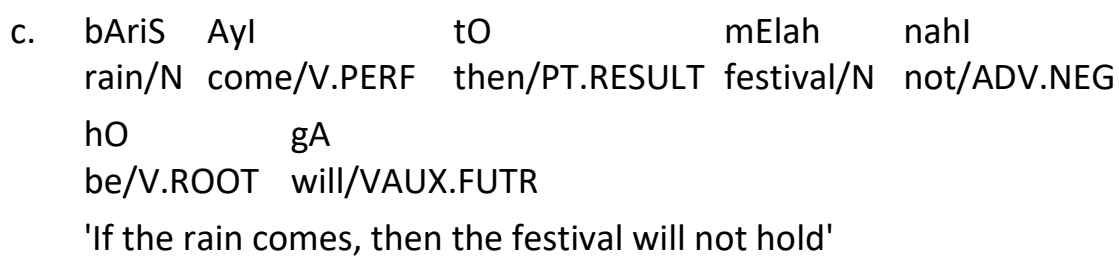

\subsection{Quantifiers}

The quantifiers $Q$ are used to show the amount of something. These are divided into four subcategories, which include Q.ADJ (adjectival quantifier), Q.CARD (cardinal quantifier), Q.FRAC (fractional quantifier) and Q.ORD (ordinal quantifier). In 14(a), the quantifiers tamAm 'all/whole', har 'every' and $d U s r A$ 'second/other' are annotated with $Q, Q . A D J$ and $Q . O R D$, respectively. The remaining subcategories of quantifiers Q.CARD and Q.FRAC are annotated in 14(b) for words $E k$ 'one' and cOtHAl 'one 4th', respectively.

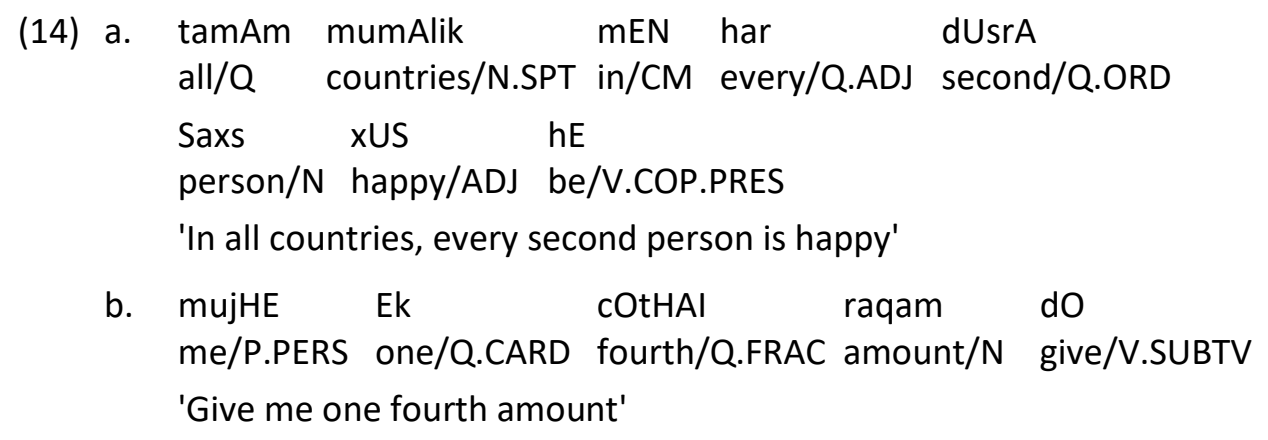

\subsection{Questions Words}

The question words QW identify a question in a sentence. These are divided into four subcategories, which include QW.REP (repeated question words), QW.TMP (temporal question words), QW.SPT (spatial question words) and QW.MNR (question words having a manner). The main category QW is depicted in 15(a) for a question word kiyA 'what'. If any question word is repeated then QW.REP can be used for annotation. The remaining three subcategories QW.TMP, QW.SPT and QW.MNR are annotated in a single sentence 15 (b) for related question words kab 'when', kidHar 'where' and kEsE 'how', respectively.
(15) a. tumhArA nAm kiyA hE ? your/P.POSS name/N what/QW be/V.COP.PRES ?/M.S 'What is your name?'
$\begin{array}{lllll}\text { b. } & \text { kab } & \text { kidHar } & \text { aOr } & \text { kEsE } \\ & \text { when/QW.TMP ,/M.P } & \text { where/QW.SPT } & \text { and/C.CORD } & \text { how/QW.MNR }\end{array}$ $\begin{array}{lll}\text { jAO } & \text { gE } & ? \\ \text { go/V.SUBTV } & \text { will/VAUX.FUTR } & \text { ?/M.S }\end{array}$
'When, where and how will you go?'




\subsection{Symbols}

The symbols SYM include brackets, parentheses, percent symbols, currency symbols, etc. All are dealt within a single category SYM as can be seen as follows.

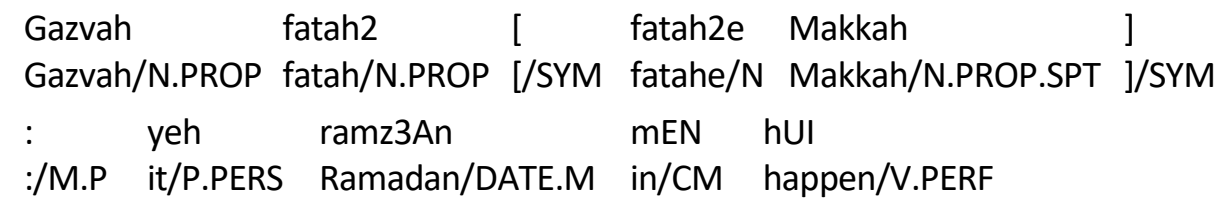

'The Battle Conquest [conquest of Makkah]: It happened in Ramadan (a month name in Islamic Calendar)'

\subsection{Titles}

The titles are used to show respect or regard to personalities before addressing their names. At present it has only one subcategory TTL.REG (regard titles). Its annotation can be seen as follows.

(17)
h2az3rat
ImAm
h2Ussyn
a2IEh-salAm
his-highness/TTL.REG religious-head/N Hussain/N.PROP AS/PRAY
tlsrE ImAm hEN
third/Q.ORD religious-head/N be/V.COP.PRES
'His highness, the religious head, Hussain (PBUH) is the third religious head'

\subsection{Units}

The Unit $U$ is used to represent different measuring units e.g., meter, liter, bar, grams, etc. The example of an annotation is given for the following sentence.
(18) qEsar $\mathrm{nE} \quad 70$
miliyan
$\tan \quad \mathrm{tEl}$
Qaiser/N.PROP CM 70/Q.CARD million/Q.CARD ton/U oil/N
darAmad kiyA
import/N do/V.LIGHT.PERF

'Qaiser imported 70 million ton oil.'

\subsection{Verbs}

The main verb $V$ is divided into 11 subcategories, which are further divided into hierarchical subcategories discussed as follows. The hierarchical division of a special 
word the $\operatorname{VALA}^{7}$ and verb auxiliaries will be discussed in respective Sections 2.21 and 2.22 .

\subsubsection{Copula Verbs}

The copula verb V.COP is used to connect the subject with the subject complement or the predicate link of a sentence (Aarts et al., 2014; Butt, 1995; Matthews, 2007; Miller et al., 1990; Stevenson, 2010). For example a sentence like The weather is horrible contains a subject The weather and a predicate link as an adjective horrible. The predicate of the sentence is the copula verb is. The copula verb connects the subject with the predicate link in this sentence. The V.COP (copula verb) is divided into six subcategories hierarchically as V.COP.IMPERF (a copula verb with imperfective morphology), V.COP.PERF (a copula verb with perfective morphology), V.COP.ROOT (a copula verb with root form), V.COP.SUBTV (a copula verb with subjunctive morphology), V.COP.PAST (copula verb with past tense) and V.COP.PRES (copula verb with present tense). The future form of copula verb itself is not possible in Urdu. In future construction, the copula verb 'be/become' always proceeds the future tense auxiliary $g A / g l / g E / g E N$ 'shall/will' as can be seen in 19(d). The V.COP.IMPERF is annotated in 19(a) for a copula verb hOtE 'be/become' in imperfective form. Its perfective form is given in 19(b). The root form of another copula verb ban 'become' (Abbas and Raza, 2014; Raza, 2011) is presented in 19(c). The subjunctive form of copula verb rahEN 'remain' (Abbas and Raza, 2014; Raza, 2011) is annotated in 19(d). The copula verb with present and the past tense $h E N / t H E$ 'are/were' is annotated in 19(e).

(19) a. Sehrl parESAn nahl hOtE hEN citizens/N worry/ADJ not/ADV.NEG be(become)/V.COP.IMPERF be/VAUX.PRES 'The citizens do not worry.'

b. xAhiS pUrl nah hUl desire/N fulfill/ADJ not/ADV.NEG be(become)/V.COP.PERF 'The desire did not become fulfilled.'

c. SIrAj acHA ban giyA Siraj/N.PROP good/ADJ become/V.COP.ROOT go/V.LIGHTV.PERF 'Siraj became good.'

d. Ith2Adl kAmyAb rahEN gE allies/N successful/ADJ remain/V.COP.SUBTV will/VAUX.FUTR 'The allies will remain successful.'

e. aEsE IOg mOjOd hEN/tHE such/ADJ people/N present/ADJ be/become/V.COP.PRES/.PAST 'Such people are/were present.'

\footnotetext{
${ }^{7}$ The VALA as a head word gives the phrase with adjectival property most likely and follows infinitive verb, nominal, adjectives, etc.
} 


\subsubsection{Imperfective Verbs}

The imperfective verb tag V.IMPERF describes actions or states occurring generally or regularly (Schmidt, 2013). It can be identified by the inflected suffixes $t A, t l, t E, t E N$ at the end of a verb. These suffixes co-exist after the root of a verb. At present, it has only one tag as V.IMPERF; however, if it is repeated then .REP can be used at the end. The example of V.IMPERF is given as follows.
(20) voh
aks2ar cOrl kartE
hEN
they/P.PERS often/ADV stealing/N do/V.IMPERF be/VAUX.PRES
'They often do stealing.'

\subsubsection{Infinitive Verbs}

An infinitive verb V.INF can be identified through its inflected suffixes $n A, n I, n E$, $n E N$ concatenated to the root form of a verb. The annotation example is given as follows.
h2akUmat
kO kAm karnA
hE
government/N CM work/N do/V.INF be/VAUX.PRES
'The government has to do work.'

\subsubsection{Light Verbs I}

A light verb V.LIGHT is a verb that contains a little semantic content of its own and it forms a predicate with some additional expression such as a noun or an adjective (Ahmed and Butt, 2011; Butt, 2003; Raza, 2011). It is subcategorized into eight different forms, which includes V.LIGHT.IMPERF (light verb with imperfective morphology), V.LIGHT.INF (light verb with infinitive morphology), V.LIGHT.PERF (light verb with perfective morphology), V.LIGHT.PROG (light verb with progressive morphology), V.LIGHT.ROOT (light verb with root form), V.LIGHT.SUBTV (light verb with subjunctive morphology), V.LIGHT.PAST (light verb with past tense) and V.LIGHT.PRES (light verb with present tense) as can be seen in 22(a)-(g) for light verbs AtA 'use to come', AnA 'to come', AyA 'came', rAhA 'remain', A 'come', dORAEN 'let to run' and thA/hE 'was/is' respectively. The respective subcategories can also be seen in Figure 1 . All the light verbs presented in annotated sentences shared their semantic content with a preceding noun $\mathrm{N}$ or adjective ADJ.
(22)
a. mUjE jin naz4ar AtA
me/P.PERS ghost/N vision/N come/V.LIGHT.IMPERF be/VAUX.PAST
'I had used to sight the ghost.'
b. mUjE jin naz4ar AnA tHA
me/P.PERS ghost/N vision/N come/V.LIGHT.INF be/VAUX.PAST
'I had to sight the ghost.'


c. mUjE jin naz4ar AyA tHA

me/P.PERS ghost/N vision/N came/V.LIGHT.PERF be/VAUX.PAST

'I had sighted the ghost.'

d. a2li kO a2lambardArl kA a2uhdah h2Asil

Ali/N.PROP CM flag-bearer/N of/CM designation/N gain/ $N$

rAhA

remain/V.LIGHT.PROG

'Ali had the designation of flag-bearer'

e. IOg taSadud bardASt nahl

people/N torture/N bear/N not/ADV.NEG

kar saktE

do/V.LIGHT.ROOT VAUX.MOD.IMPERF

'The people can not bear the torture'

f. ham naqSE par naz4ar dORAEN gE we/P.PERS map/N on/CM vision/N run/V.LIGHT.SUBTV will/VAUX.FUTR 'We will look on the map'

g. SirAj pUrAnE AdmION mEN SAmil thA/hE Siraj/N.PROP old/ADJ persons/N in/CM include/N was/is/V.LIGHT.PAST/PRES 'Siraj was/is included in old persons'

\subsubsection{Light Verbs II}

A light verb V.LIGHTV is a verb that contains a little semantic content of its own and it forms a predicate in the presence of an additional verb (Butt, 2003), hence is called as the verb-verb complex predicate. It is subcategorized into five different forms, which include V.LIGHTV.IMPERF, V.LIGHTV.INF, V.LIGHTV.PERF, V.LIGHTV.ROOT and V.LIGHTV.SUBTV as can be seen in 23(a)-(e) for light verbs kartA 'used to do', dEnA 'to give', liyA 'took', hO 'be/become' and $j A y E$ 'should go' respectively. All the light verbs presented in the annotated sentences as follows shared their semantic content with a preceding verb $\mathrm{V}$ or a light verb V.LIGHT.

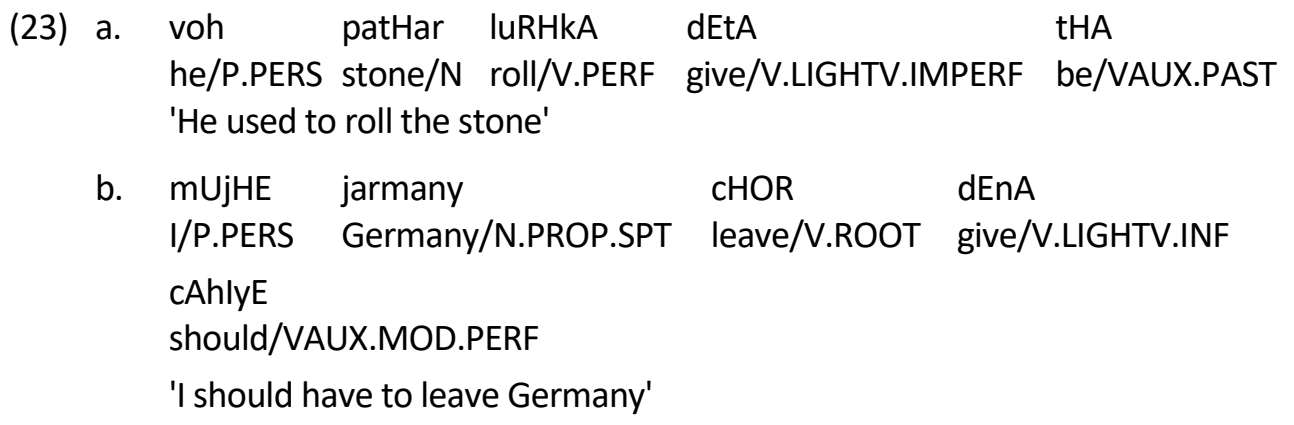




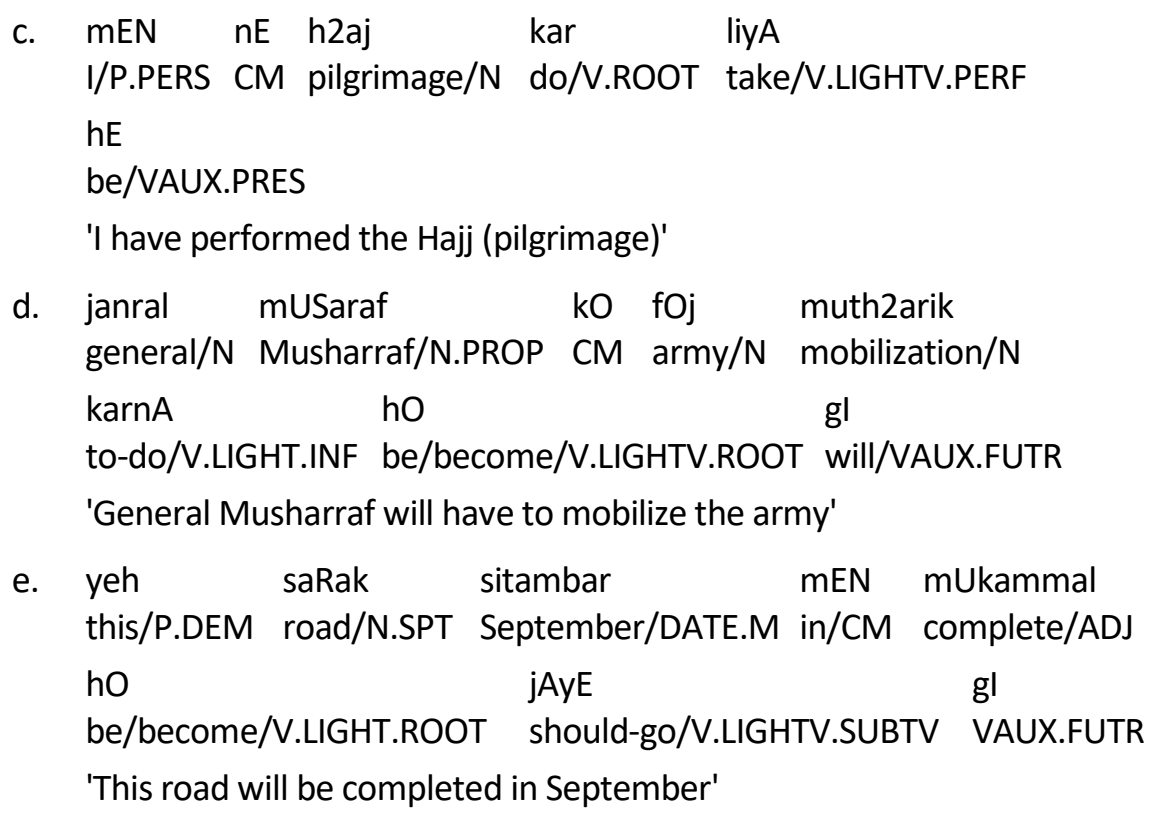

\subsubsection{Modal Verbs}

A modal verb V.MOD expresses a scale ranging from possibility to necessity (Abbas and Nabi Khan, 2009). It is subcategorized into three morphological forms, which includes V.MOD.IMPERF (modal verb with imperfective morphology), V.MOD.PERF (modal verb with perfective morphology) and V.MOD.SUBTV (modal verb with subjunctive morphology). This category of modal verbs is different from modal auxiliaries discussed in Section 2.22.3, in which the main verb (predicate) of the sentence is annotated with $V$ and the modal auxiliaries are annotated with VAUX. The examples of cAhnA 'may want to' modified from Facchinetti et al. (2003) contain modal verb V.MOD acting as the predicate of the respective sentence and not as an auxiliary, and are presented as follows.

(24) a. voh kitAb paRHnA cAhtA hE he/P.PERS book/N read/V.INF want/V.MOD.IMPERF be/VAUX.PRES 'He may wants to read the book.'

b. tUm $n E$ intEqAm IEnA cAhA tHA you/P.PERS CM revenge/N take/V.INF want/V.MOD.PERF be/VAUX.PAST 'You might have wanted to take the revenge'

c. voh intEqAm IEnA cAhEN gE they/P.PERS revenge/N take/V.INF want/V.MOD.SUBTV will/VAUX.FUTR 'They will want to take a revenge' 


\subsubsection{Perfective Verbs}

A verb with perfective morphology V.PERF can be identified through its inflected suffix e.g. $A, I, E, E N$ concatenated to the root form of a verb. The annotation examples can be seen in 25 for a verb kahA 'said' in (a) and giyA 'went' in (b). The repetition of same verb can be annotated as V.PERF.REP. More examples can be seen in $3(d, e), 8(b)$, 9(d), 13(c) and 16.
(25) a. rasUl $\mathrm{nE}$ kahA
prophet/N CM said/V.PERF
'The prophet said'
b. voh pOlls $\mathrm{kE}$ pAs giyA
he/P.PERS police/N CM to/POSTP went/V.PERF
'He went to the police'

\subsubsection{Root Verbs}

A verb with root form is a verb to which suffixes can be added (Schmidt, 2013). An annotated example can be seen in 26 for a verb $A$ 'come', whose infinitive form is $A n A$ 'to come'. More examples can be seen in $3(b)$ and $13(c)$. The repetition of same verb can be annotated as V.ROOT.REP.
(26) voh yahAN dOrAnE taftIS A he/P.PERS here/ADV.SPT during/PREP.TMP investigation/N come/V.ROOT giA
go/V.LIGHTV.PERF
'He came here during the investigation'

\subsubsection{Subjunctive Verbs}

A subjunctive verb is a verb used to express hypothetical actions or conditions (Dic, 2014; Schmidt, 2013). Annotated examples can be seen in 2(e) and 15(b) for the subjunctive form of the verbs $A y I N$ 'come' and $j A O$ 'go' respectively.

\subsubsection{Verb With Tense}

There are sentences, the structures of which look like copular constructions but the argument requirement (subject and predicate link) for their predicates cannot be fulfilled. It means that either the subject or the predicate link is missing in these types of sentences. The structure of these types of sentences is closer to existential copula construction in English. For example, the sentence There is the God has an existential copular construction (Raza, 2011). The translation of this sentence in Urdu is $x U d A / G o d$ 
$h E /$ is with one argument for an existential copula verb is. Due to incomplete arguments in these type of sentences only, the copula verb V.COP.PRES/PAST is reduced to V.PRES/PAST for present and past tense as follows.
(27) $\mathrm{mErl}$
xAhiS $\quad \mathrm{tHI} / \mathrm{hE}$
my/P.POSS desire/N be/V.PAST/PRES

'It is my desire'

\subsection{Special VALA}

The VALA is a special word in Urdu, which normally appears in a noun or an adjective phrase. It can also express the action that is going to start in a special way as can be seen in 28(a). Another reading of the same sentence is also mentioned. A single tag VALA is used to represent all types of VAIA morphological forms. Example given in 28(b) has a nominal reading.
$\begin{array}{llll}\text { a. } & \text { MEN } & k A m & k a r n E \\ & \text { I/P.PERS } & \text { work/N } & \text { to-do/ }\end{array}$
vAIA
hUN
I/P.PERS work/N to-do/V.INF going/has/VALA be/V.COP.SUBTV
'I am going to do work or I am a working person' (two different readings)
b. mEN dUdH VAIA hUN
I/P.PERS milk/N has/VALA be/V.COP.PRES
'I am the milkman'

\subsection{Verb Auxiliaries}

Verb auxiliaries VAUX denote the tense, aspect, modality, voice, mood, emphasis, etc., of the sentence predicate (Aarts et al., 2014). In Urdu, a predicate or a complex predicate in the main verb phrase of the sentence precedes verb auxiliaries e.g., hO/V.COP.ROOT gayl/V.LIGHTV.PERF hE/VAUX.PRES 'has/have become' contains a tense auxiliary VAUX.PRES along with the complex predicate $h O$ gayl. Verb auxiliaries are divided into 11 subcategories discussed as follows.

\subsubsection{Imperfective Auxiliaries}

The method of identification for the imperfective auxiliary VAUX.IMPERF is the same as was discussed in Section 2.20.2 of imperfective verbs V.IMPERF. It is a single sub- category with no any further divisions. An annotated example for this subcategory is given as follows.

(29) kEs invesTigESan pOlls kE pAs calA case/N investigation/N police/N CM to/POSTP walk/V.PERF

jAtA hE go/VAUX.IMPERF be/VAUX.PRES

'The case (usually) goes to investigation police' 


\subsubsection{Infinitive Auxiliaries}

The identification of infinitive auxiliaries VAUX.INF is the same as was discussed in Section 2.20.3 of infinitive verbs V.INF. It is also a single subcategory, whose annotated example is presented for jAnE 'to go' as follows.
(30) Ap
a2rab
qabAyl mEN pehcAnE
jAnE
he/P.PERS Arab/N.SPT tribes/N in/CM recognize/V.INF go/VAUX.INF
lagE
tHE
take/VAUX.PERF be/VAUX.PAST
'He had become known in Arab tribes'

\subsubsection{Modal Auxiliaries}

A modal auxiliary VAUX.MOD expresses a range from possibility to necessity (Abbas and Nabi Khan, 2009; Bhatt et al., 2011). It is subcategorized into three morphological forms, which include VAUX.MOD.IMPERF (modal auxiliary with imperfective morphology), VAUX.MOD.PERF (modal auxiliary with perfective morphology) and VAUX.MOD.SUBTV (modal auxiliary with subjunctive morphology). These modal auxiliaries are different from the modal verbs discussed in Section 2.20.6, in which the modal verbs were acting as the predicate of the sentence but here the modal auxiliaries are following the predicate of the sentence. The examples for modal auxiliaries are as follows for saktE 'can', cAhlyE 'should' and paREN 'has/have to'.
a. voh
baRE
h2Ads2
kA sabab
ban they/P.PERS big/ADJ.DEG accident/N of/CM reason/N become/V.COP.ROOT saktE hEN
can/VAUX.MOD.IMPERF be/VAUX.PRES
'They can become the reason of a big accident'
b. kAm xatam kar dEnA cAhlyE work/N finish/N do/V.LIGHT.ROOT give/V.LIGHTV.INF should/VAUX.MOD.PERF 'The work should be finished'
c. vATar kOnsal kAnUnl mUSgAflyAN Water/N.PROP Council/N.PROP CM regulation/ADJ anomalies/N $\begin{array}{llll}\text { dUr } & \text { karnl } & \text { paREN } & \text { gIN } \\ \text { far/ADJ } & \text { do/V.LIGHT.INF } & \text { has/haveto/VAUX.MOD.SUBTV } & \text { will/VAUX.FUTR }\end{array}$ 'The Water Council will have to remove the regulation anomalies'

\subsubsection{Passive Auxiliaries}

In sentences with passive auxiliaries VAUX.PASS, the theme/patient becomes the grammatical subject of the main verb. It is divided into five subcategories, which includes VAUX.PASS.IMPERF (passive auxiliary with imperfective morphology), VAUX. 
PASS.INF (passive auxiliary with infinitive morphology), VAUX.PASS.PERF (passive auxiliary with perfective morphology), VAUX.PASS.ROOT (passive auxiliary with root form), and VAUX.PASS.SUBTV (passive auxiliary with subjunctive morphology). The given examples have a morphological annotation of passive auxiliaries jAtA 'use to go', jAnA 'to go', giyA 'went', jA 'go' and jAyEN 'may go' respectively. These different forms of $j A$ 'go' auxiliary are considered passive only, when they are preceded by a predicate or a complex predicate with perfective morphology (Raza, 2010).

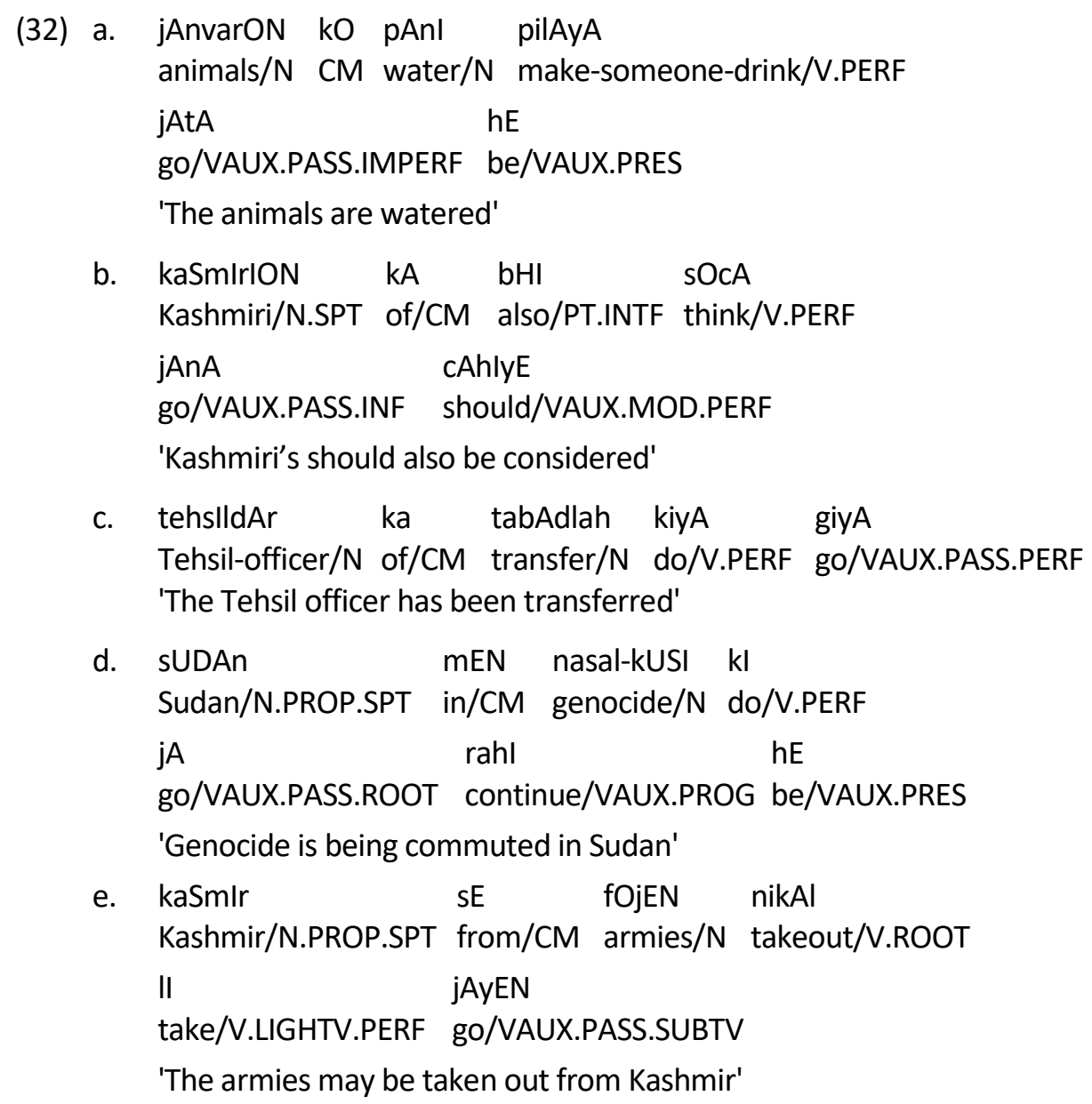

\subsubsection{Perfective Auxiliaries}

The identification of perfective auxiliary VAUX.PERF is the same as was discussed in Section 2.20.7 of perfective verbs. It is an independent single subcategory, whose annotation is given in the following example.

(33) IOgON $\mathrm{kE}$ ravalyON mEN tabdeell Atl gayl people/N of/CM behavior/N in/CM change/N come/V.IMPERF go/VAUX.PERF 'The change used to come in people's behaviors' 


\subsubsection{Progressive Auxiliaries}

The progressive auxiliary VAUX.PROG can be identified easily through its morphological form after a verb or an auxiliary. Its morphological forms include rahA, rahE, rahl, rahIN. An annotated example can be seen in 32(d) for a progressive auxiliary rahl 'continue'.

\subsubsection{Root Auxiliaries}

The identification of an auxiliary with a root form VAUX.ROOT is the same as discussed in Section 2.20.8 for verbs with root morphology. An annotated example is given as follows.
(34) faqlr
baRHtE
jA
rahE
hEN
beggars/N increase/V.IMPERF go/VAUX.ROOT continue/VAUX.PROG be/VAUX.PRES 'The beggars are increasing'

\subsubsection{Subjunctive Auxiliaries}

A subjunctive verb auxiliary VAUX.SUBTV describes an uncertain action or state contingent on something else like permission, wish, request, etc., (Schmidt, 2013). It has no further divisions. An annotated example of subjunctive auxiliary is given as follows.
(35) kiyA mEN andar AyUN ?
what/QW I/CM In/ADV.SPT come/VAUX.SUBTV ?/M.S
'May I come in?'

\subsubsection{Tense Auxiliaries}

The tenses of auxiliary VAUX are divided mainly into three tense divisions, which include VAUX.FUTR (future tense auxiliary e.g. $g A, g l, g E, g I N$, etc.), VAUX.PAST (past tense auxiliary e.g. $t H A, t H I, t H E, t H E N$, etc.) and VAUX.PRES (present tense auxiliary e.g. $h E, h E N$, etc.). The annotation of the future tense auxiliary can be seen in 36(a). The annotation of past tense auxiliary is presented in 36(b). Similarly, the annotation of last subcategory VAUX.PRES is annotated in 36(c).

(36) a. ham naqSE par naz4ar dORAEN gE we/P.PERS map/N on/CM vision/N run/V.LIGHT.SUBTV will/VAUX.FUTR 'We will look on the map'

b. ham naqSE par naz4ar dORA we/P.PERS map/N on/CM vision/N run/V.LIGHT.PERF

rahE tHE continue/VAUX.PROG be/VAUX.PAST 
'We were looking on the map'

c. ham naqSE par naz4ar dORA we/P.PERS map/N on/CM vision/N run/V.LIGHT.PERF

rahE hEN

continue/VAUX.PROG be/VAUX.PRES

'We are looking on the map'

Tags presented in Figure 1 have been completed along with the examples. The discussion in this Section 2 concludes the SSP guidelines for the URDU.KON-TB treebank.

\section{The URDU.KON-TB Treebank}

The development of the URDU.KON-TB treebank was performed in three steps: the collection of sentences in the form of a corpus, manufacturing of an annotation scheme and the employment of this annotation scheme on the said corpus. These steps are overviewed as follows. In initial development of the URDU.KON-TB treebank (Abbas, 2012), a POS, a syntactic and a functional tag sets were proposed. It was an original work done after getting motivation from the Penn treebank ${ }^{8}$ and the Urdu Lexical Functional Grammar (LFG) built during a project called PARGRAM ${ }^{9}$. This work has some issues, which were resolved and updated after the annotation evaluation (Abbas, 2014a \& 2014b). The updated versions of the tag sets have been presented and discussed earlier in Section 2.

\subsection{Corpus Construction}

In initial development (Abbas, 2012), a 19 million words corpus (Ijaz and Hussain, 2007) was used that was available at CRULP/CLE. ${ }^{10}$ This corpus was collected from the Jang $^{11}$ and the $\mathrm{BBC}^{12}$ newspapers. This corpus had licensing constraints due to which it is not publicly available anymore (Urooj et al., 2012). One thousand (1000) sentences taken from this corpus are then extensively modified to become free from licensing constraints, because we want to share our corpus freely under a Creative Commons Attribution/Share-Alike License 3.0 or higher. The next four hundred (400) sentences are collected from the Urdu Wikipedia. ${ }^{13}$ The data collected from the Urdu Wikipedia

\footnotetext{
${ }^{8}$ http://www.cis.upenn.edu/ treebank/home.html

${ }^{9} \mathrm{http}: / /$ ling.uni-konstanz.de/pages/home/pargram_urdu/

${ }^{10}$ A center for language engineering in Pakistan at http://cle.org.pk/

${ }^{11}$ http://jang.com.pk/

12 http://www.bbc.co.uk/urdu/

${ }^{13}$ https://ur.wikipedia.org
} 
is already under that license. Thus, the size of the corpus is limited to fourteen hundred (1400) sentences. The size of corpus is kept limited within the context of doctoral work (Abbas, 2014b), however, an extension project ${ }^{14}$ to increase the size of the treebank up to 2000 sentence is completed and will be published soon. Overall, the corpus contains the text of local \& international news, social stories, sports, culture, finance, history, religion, traveling, etc.

\subsection{Annotation Scheme}

The annotation scheme of the URDU.KON-TB treebank consists of semi-semantic POS (SSP), semi-semantic syntactic (SSS) and functional (F) tag sets. The term semisemantic (partly or partially semantic) is used with the POS because some tags are encoded with semantics but not all e.g. N.SPT (a spatial noun) tag for a word house, ADJ.TMP (a temporal adjective) tag for a word previous in previous year, etc. At the SSP level, a dot '.' is used to add morphological (Figure 3) and semantical (Figure 4) labelings of subcategories into the main categories (Figure 2) as discussed in Section 3.3. Overall, for the SSP, SSS and F annotation, a combination of phrase structure (PS) and hyper dependency structure (HDS) has been adopted. The DS is called HDS because it is not limited to make constituents on the basis of headwords, but also on the basis of the head-constituents, when you have to make a constituent from its nested constituents. The details are given in Abbas (2014b). The POS, morphological, syntactical, semantical, clausal and functional information (Abbas, 2014b) all together, makes a rich annotation scheme for the URDU.KON-TB treebank. The need for such type of schemes is highly advocated by some researchers, such as Clark et al. (2010), Skut et al.(1997), etc.

\subsection{Employment of Annotation}

A simple POS tag set was devised first, which contained twenty two (22) main POStag categories displayed in Figure 2. The description of the tags is given in the respective cells of the figure. The figure includes some non-familiar tags like HADEES and MARKER to represent the Arabic statements of prophets in Urdu text and a phrase or a sentence marker similar to punctuation marks but not all, respectively. The labels for morphological and semantic subcategories are presented in Figures 3 and Figure 4 respectively, which can be added to 22 main categories of POS tags by using a dot '.' symbol. The SSP tag set was refined during the manual annotation process of sentences and further refined after the evaluation process with the Krippendorf's $\alpha$ statistical model (Krippendorf, 2014) and also presented in Abbas (2014a). The final refined form of the SSP tag set is given in Figure 1. In case of morphology, if a main verb $V$ has a perfective morphology, then the tag becomes V.PERF. Similarly, the case of spatial noun N.SPT is discussed in the beginning of Section 3.2. The semantic tags like SPT

\footnotetext{
${ }^{14}$ http://clsp.org/projects.html
} 
(spatial), TMP (temporal), MNR (manner), etc. are not possible with verbs, auxiliaries, conjunctions, etc., as can be seen in Figure 1.

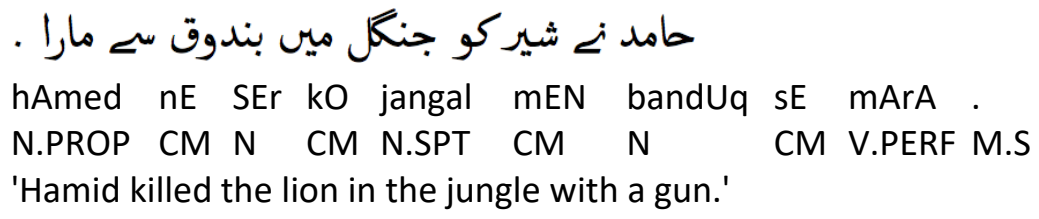

An example of the SSP annotation is given in Example 37. The Urdu script is written from right to left. The row beneath the Urdu script is the transliteration of the sentence as proposed in Malik et al. (2010). The tokens of the sentence are tagged according to the SSP tag set. $h A m e d$ is a proper name (N.PROP). SEr and bandUq are common nouns $(\mathrm{N})$, while jangal is a spatial common noun (N.SPT). ${ }^{15} n E, k O, m E N$, and $s E$ are case markers (CM) for ergative, accusative, spatial/locative and instrumental cases, respectively. The syntactic differentiation of the case markers is done according to the studies in Butt and King (2004).

The tagset in Figure 1 represents the complete SSP tagset. The discussion on each tag is presented in Section 2. As a repeated example, consider the ADJ (Adjective) in Figure 1 , which is divided into five subcategories of tags DEG (Degree), ECO (Echo), MNR (Manner), SPT (Spatial) and TMP (Temporal). Relevant examples are provided in 38.

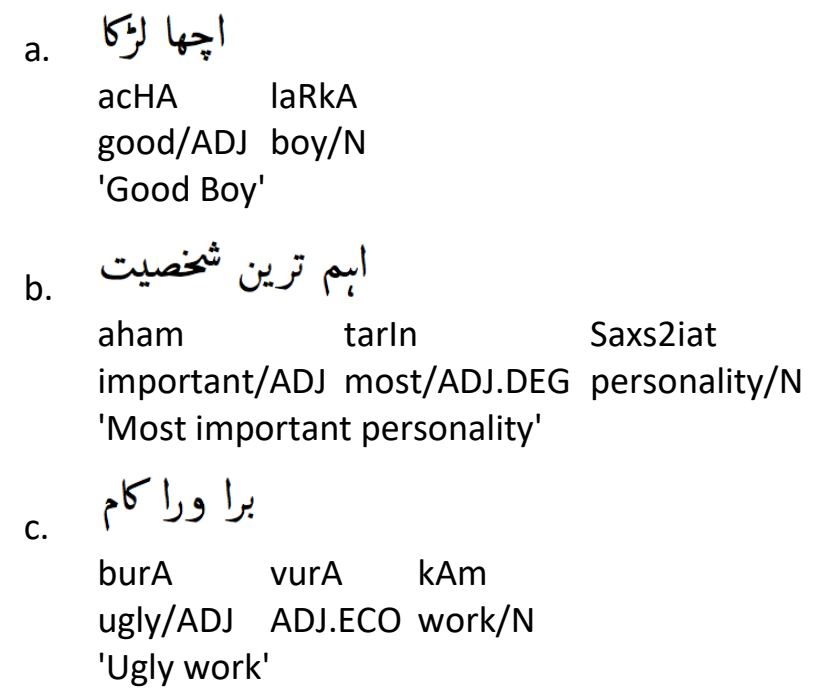

\footnotetext{
${ }^{15}$ In the presence of a sense of place/location or direction to/from place/location in a word, SPT tag is used e.g. Pakistan and the country, are the two words. Pakistan is the proper name of a place (country) and is tagged as N.PROP.SPT. However, country is a common noun but having a sense of place. So, it is tagged as N.SPT. This distinction is not different from spatial adverbs e.g. there, here, etc.
} 
d.

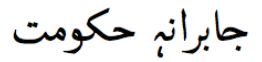

jaberaanah

hakUmat

cruel/ADJ.MNR government/N

'Cruel Government'

e.
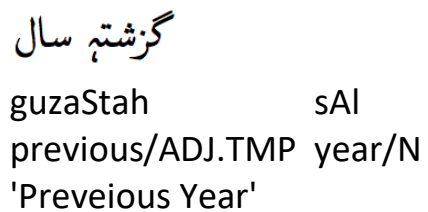

f.

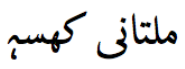

mUltAnl kHUsah

multani/ADJ.SPT shoe/N

'Multani shoe'

The example 38(a) is a simple case of ADJ, while $38(b)$ is a case of a degree adjective $^{16}$ annotated with ADJ.DEG. The comparative and superlative forms of adjectives can be made by introducing Persian suffixes tar 'more' and tarln 'most' after the absolute form of adjectives e.g. xUbs3Urat-tar 'prettier' and xUbs3Urat-tarln 'prettiest'. There are some words, which can play the role of a degree adverb or a degree adjective e.g. zEyAdah 'more/most/much', bohat 'more/enough', kAfI 'quite/too', etc. (Schmidt, 2013). If these words qualify adjectives, then this is the usage as degree adverbs, otherwise as a degree adjective. Example 38(c) is a case of reduplication (Abbi, 1992; Boegel et al., 2007). As reduplication has two versions, first in Urdu like other South Asian languages, the reduplication of a content word is frequent. Its effect is only to strengthen the proceeding word or to expand the specific idea of a proceeding word into a general form e.g. kAm THIk-THAk karnA 'Do the work right' or kOI kapRE-vapRE $d E d O$ 'Give me the clothes or something like those'. Second version is the repetition of the original word e.g. $s A t H s A t H$ 'with/along-with'. These two versions are named as full word reduplication and echo reduplication by Boegel et al. (2007), which are represented in our annotation as ECO (echo) and REP (repetition) respectively. The echo words normally begin with the letters $S$ or $v$ or $m$.

Example 38(d) is the case of adjective having a sense of manner annotated as ADJ.MNR. If an adjective qualifies an action noun, then a sense of action or something is produced, whose behavior or the way to do that action is confirmed through ADJ.MNR e.g. z4AlemAnah t2abdIllyAN 'brutal changes'. If an adjective comes individually, then its mannerism can be resolved independently through its sense or by building a sense with the predicate. If there is a sense of manner then an adjective of manner can exist like in copular construction e.g. voh GEr-h2Az3ir hE 'He is absent'. An exercise of adjectives and adverbs of manner for the English language can be seen at Cambridge

\footnotetext{
${ }^{16}$ This division is used to represent absolute, comparative and superlative degree in adjectives and adverbs.
} 
University from which this idea is taken ${ }^{17}$ Example $38(\mathrm{e})$ is case of an adjective having a temporal sense. Finally, example $38(\mathrm{f})$ is the case of an adjective having a spatial sense. The adjective used here is the derivational form of a city/place name Multan, which is a spatial proper noun. But it appears here as an adjective and annotated as ADJ.SPT ${ }^{18}$ like in this sentence e.g. voh Ek pAkistAnl laRkA hE 'He is a pakistani boy'.

The example 38 for adjectives exploited its POS tags along with semantic tagging like TMP, SPT, MNR, etc. However, to give an introduction about morphology and verb functions, another POS category $V$ from Figure 1 is discussed as follows. A few high quality studies were conducted on verbs for morphologically rich language (MRL) Urdu by Butt and Rizvi (2010), Butt and Ramchand (2001) and Butt (2010). The rules for identifying different forms of verbs were adopted from these studies. The $V$ annotates the predicate/main-verb of the sentence and is divided mainly into 11 subcategories, which include COP (copula verb), IMPERF (imperfective morphological form of the verb), INF (infinitive form of verb), LIGHT (1st light verb with nouns and adjectives), LIGHTV (2nd light verb with verbs), MOD (modal verb), PERF (perfective morphology), ROOT (root form), SUBTV (subjunctive form), PAST (past tense of a verb) and PRES (present tense of a verb). Their description is also given in Figure 1. These tags are further divided into subcategories depicted in Figure 1. All these tags represent different morphological forms and the function of a verb that it governs. Some annotated sentences containing different verb forms and functions are given in example 39.

(39) a.

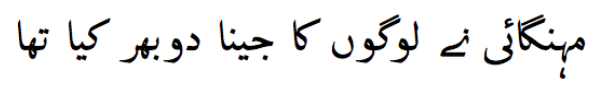

mehangAl $\mathrm{nE}$ IOgON kA jInA dUbHar kiyA tHA $\mathrm{N} \quad \mathrm{CM} N \quad \mathrm{~N} \quad \mathrm{~N} N \mathrm{~N} \quad$ V.LIGHT.PERF VAUX.PAST

'The inflation had made the life of people hard.'

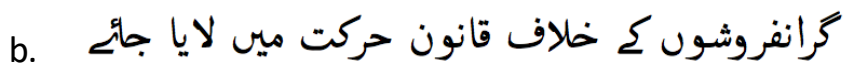
giraN-faroSoN kE xilAf qAnUn harkat mEN IAyA jAyE $\mathrm{N} \quad \mathrm{CM}$ POSTP.MNR N N CM V.PERF VAUX.PASS.SUBTV 'The law should be practiced against inflators'

c.

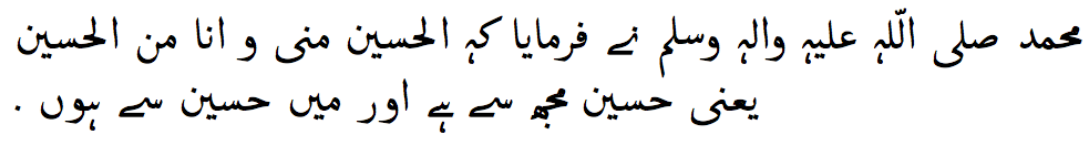

mUhammad sal-lal-la-ho-a2lEhE-va-AlEhl-salam nE farmAyA keh N.PROP PRAY CM V.PERF C.SBORD “ al-hUsynON-mInnl-vA-anA-mInal-hUsyn " ya2nl ' hUsyn M.P HADEES M.P ADV M.P N.PROP

\footnotetext{
${ }^{17}$ http://www.cambridge.org/grammarandbeyond/wp-content/uploads/2012/09/Communicative _Activity_Hi-BegIntermediate-Adjectives_and_Adverbs.pdf

${ }^{18}$ Spatial adjectives are used to describe a place/location, direction or distance e.g. multAnl 'Multani', agll 'next', and dUr 'far' respectively.
} 
mUjH $s E$ hE aOr mEN hUsyn $s E$ hUN ' .

P.PERS CM V.COP.PRES C.CORD P.PERS N.PROP CM V.SUBTV M.P M.S

'Muhammad (May Allah grant peace and honor on him and his family) said that

"al-hUsynON-mInnI-vA-anA-mInal-hUsyn" means "Hussain is from me and I am

from Hussain'.'

d.

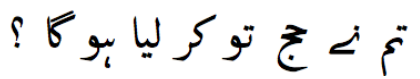

tUm nE haj tO kar liyA hO gA ?

P.PERS CM N PT.EMP V.ROOT V.LIGHTV.PERF VAUX.SUBTV VAUX.FUTR M.S

'You will have made the pilgrimage?'

e.

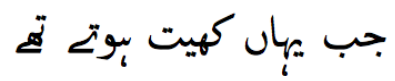

jab yahAN kHEt hotE tHE

ADV.TMP.REL ADV.SPT N.SPT V.IMPERF VAUX.PAST

'When, here would have been crop fields'

f.

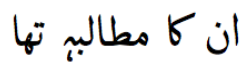

Un kA mUtAlibah tHA

P.PERS CM N V.PAST

'It is their demand.'

The sentence in example 39(a) is a case of noun-verb complex verb predicate, which was first proposed by Mohanan (1994). The words dUbHar kiyA 'made hard' is a noun-verb complex predicate. The noun dubHar and the verb kiyA with a perfective morphological form $y A$ at the end are annotated as a $\mathrm{N}$ and a V.LIGHT.PERF respectively. Similarly, a perfective verb liyA 'took' after a root form of verb kar 'do' is an example of the verb-verb complex predicate depicted in $39(\mathrm{~d})$. This construction is adopted from the studies given in (Butt, 2010). The light verb after a N or an ADJ lies in the 1st category of light verbs and annotated as V.LIGHT in our annotation, while the light verb after a verb lies in the 2 nd category of light verbs and annotated as V.LIGHTV. The next sentence in $39(\mathrm{~b})$ is a passive sentence. A passive construction can be concluded with the inflected form of a verb jAnA 'to go' proceeded by another verb with perfective morphology as can be seen in 39(b). The subjunctive form of auxiliary verb tagged as VAUX.PASS.SUBTV is preceded by a perfective verb IAyA 'brought', which is then annotated as V.PERF. The subjunctive form of verb is acting as an aspectual auxiliary and not as a V.LIGHTV, which was discussed in (Butt and Ramchand, 2001) and adopted as it is. The rules for identification of verb function and other morphological forms can be found in Section 2.

To explore some other unusual tags, a long sentence is presented in 39(c). After the name of prophets or righteous religious-personalities, some specific and limited prayers called s3alAvAt 'prayers' e.g. sal-lal-la-ho-a2IEhE-va-AlEhl-salam 'May Allah grant peace and honor on him and his family', a2IEh salAm 'peace be upon him', etc. in Arabic is most likely in Urdu text and annotated as PRAY. Similarly, the statements of 
prophet Muhammad (PBUH) called h2adls2 'narration' e.g. In-namal-aa2mAlo-binniyAt 'The deeds are considered by the intensions' in Arabic is also a tradition in Urdu text and annotated as HADEES. In religious text of Urdu, this kind of phenomenon is most likely in Arabic script rather than the Urdu script. This annotation with PRAY and HADEES is performed only, when prayers or narrations appear in Arabic language in Urdu text as can be seen in 39(c). The phrase markers like comma, double quotes, single quotes, etc. are annotated with M.P and sentence marker like full stop, question mark, etc. are annotated with M.S as presented in the same example. The tense is divided into present, past and future. A predicate of the sentence with present and past tense is possible as annotated in 39(f) but not with future tense, because future tense always behaves as verb auxiliary in Urdu. The tense of verb auxiliaries like present, past and future is annotated in 39(a, d, e). A verb with imperfective morphology e.g. $t A, t l, t E$, $t E N$ at the end of a verb is annotated with V.IMPERF as given in 39(e).

This section concludes the concept of SSP tags used in the annotation of the URDU.KON-TB treebank. There are twenty-two tags, which are divided into further subcategories as presented in Figure 1 . The POS annotation evaluation via Krippendorf's Alpha $\alpha$ is detailed in (Abbas, 2014a \& 2014b), however an overview is presented next in Section 4. This evaluation came up with POS tags issues related to readability. After evaluation, the problematic POS tags are either removed or revised and a final SSP tagset is obtained and presented.

\section{Evaluation and Results}

This Section describes the evaluation of the annotation guidelines of the URDU.KON-TB treebank presented in Section 2 and 3. The evaluation is the process of calculating inter-annotator agreement (IAA), which provides a quantitative answer as to the overall consistency plus feasibility of the annotation scheme. For the evaluation of the URDU.KON-TB treebank annotation, the most advanced measure known as the Krippendorf's a coefficient (Krippendorf, 2004) is used. The output of the annotators is recorded and processed. The reliability of the SSP annotations is evaluated. The issues faced in annotation evaluation are removed via respective revisions and are reported shortly in forthcoming sections.

\subsection{Setup}

For the reliability evaluation of annotation guidelines presented in Section 2 of the URDU.KON-TB treebank for Urdu, it was essential that annotators should be the native speakers of Urdu possessing linguistics skills. To fulfill this purpose, an undergraduate class of 25 linguistics students has been adopted in the training course of annotation at Department of English, University of Sargodha, Pakistan. ${ }^{19}$ This training was given to

\footnotetext{
${ }^{19}$ http://uos.edu.pk/
} 
students as a partial part of their major course of linguistics. During this training course, thirty-two (32) lectures on annotation guidelines with practical sessions were delivered. The duration of each lecture was of 3 hours. The class was further divided into five groups and during their initial practical sessions, one student with high caliber of understanding was selected (but not informed) secretly from each group for the final annotation. The annotation task of 100 random sentences was divided into 10 home assignments. Each assignment contained 10 sentences. After twenty days of this course, the annotation assignments were given to all students along with the selected students with an instruction not to discuss it with each other. These assignments were collected, marked and the students were awarded with grades. The annotation performed in their home assignments by the selected students was then recorded in Microsoft Excel and evaluated for the reliability of annotation or IAA by applying the Krippendorf's $\alpha$ coefficient. The details of the SSP annotation evaluation can be seen in Section 4.2.

\subsection{SSP Tagset Evaluation \& Results}

The detail and definition of the SSP tagset was already described in Sections 2 and 3. The complete guidelines of the SSP tagging were given to students for annotation of sentences according to a procedure described in Section 4.1. The tagged sentences by the annotators were recorded in the form of a reliability data matrix. Details are given in the doctoral thesis by Abbas (2014b). From the reliability data matrix, values by tokens matrix was obtained which is also presented in Abbas (2014b). The $\alpha$ coefficient was computed according to the formula given in equation below and also described in Abbas (2014b). In this work, different variables of numerator and denominator of equation were computed and described. The value of the $\alpha$ coefficient obtained was 0.964 for the SSP tagging of annotators. The value of $\alpha$ obtained lied in the category of perfect agreement according to the Krippendorf. A perfect agreement of 0.964 has been found in case of the SSP annotation only, which means that the SSP annotation guidelines are reliable. The error analysis and discussion of issues related to SSP tag set evaluation is given in Abbas (2014b) but not discussed here due to the scope of this article.

$$
\text { metric } \alpha=1-\frac{O_{d}}{E_{d}}=1-(n . .-1) \frac{\sum_{t} \frac{1}{n_{t}-1} \sum_{p} \sum_{q>p} n_{t p} n_{t q} \text { metric }_{p q}^{\delta^{2}}}{\sum_{p} \sum_{q>p} n_{. p} n_{. q} m e t r i c_{p q}^{\delta^{2}}}
$$




\begin{tabular}{|c|c|c|c|c|c|}
\hline ADV & 30 & 30 & 0 & & 100.00 \\
\hline ADV.DEG & 10 & 10 & 0 & & 100.00 \\
\hline ADV.MNR & 20 & 20 & 0 & & 100.00 \\
\hline ADV.NEG & 10 & 10 & 0 & & 100.00 \\
\hline ADV.SPT & 20 & 20 & 0 & & 100.00 \\
\hline ADV.TMP & 70 & 70 & 0 & & 100.00 \\
\hline C.CORD & 30 & 30 & 0 & & 100.00 \\
\hline $\mathrm{CM}$ & 630 & 630 & 0 & & 100.00 \\
\hline DATE.Y.CAL & 20 & 8 & 12 & DATE.Y & 40.00 \\
\hline DIA.IZF & 90 & 39 & 51 & DIA & 43.33 \\
\hline DIA.PESH & 10 & 3 & 7 & DIA & 30.00 \\
\hline KER & 150 & 71 & 79 & $\mathrm{CM}$ & 47.33 \\
\hline $\mathrm{N}$ & 1010 & 1005 & 5 & BLANK, N.SPT & 99.50 \\
\hline N.PROP & 80 & 80 & 0 & & 100.00 \\
\hline N.PROP.SPT & 10 & 10 & 0 & & 100.00 \\
\hline N.SPT & 60 & 56 & 4 & $\mathrm{~N}$ & 93.33 \\
\hline N.TMP & 60 & 60 & 0 & & 100.00 \\
\hline P.DEM & 50 & 50 & 0 & & 100.00 \\
\hline P.INDF & 10 & 10 & 0 & & 100.00 \\
\hline P.PERS & 200 & 197 & 3 & P.PRO & 98.50 \\
\hline P.POSS & 10 & 8 & 2 & P.PERS & 80.00 \\
\hline P.POSS.REF & 10 & 10 & 0 & & 100.00 \\
\hline P.REL & 10 & 10 & 0 & & 100.00 \\
\hline POSTP & 60 & 60 & 0 & & 100.00 \\
\hline POSTP.CMP & 30 & 25 & 5 & POSTP & 83.33 \\
\hline POSTP.SPT & 20 & 20 & 0 & & 100.00 \\
\hline POSTP.TMP & 20 & 20 & 0 & & 100.00 \\
\hline PREP & 20 & 20 & 0 & & 100.00 \\
\hline PT & 20 & 9 & 11 & PT.INTF & 45.00 \\
\hline PT.INTF & 30 & 13 & 17 & PT & 43.33 \\
\hline Q & 30 & 30 & 0 & & 100.00 \\
\hline Q.CARD & 210 & 210 & 0 & & 100.00 \\
\hline Q.FRAC & 20 & 20 & 0 & & 100.00 \\
\hline Q.ORD & 40 & 36 & 4 & Q.CORD, Q.CARD & 90.00 \\
\hline QW & 50 & 50 & 0 & & 100.00 \\
\hline U & 30 & 30 & 0 & & 100.00 \\
\hline V.COP.IMPERF & 20 & 20 & 0 & & 100.00 \\
\hline V.COP.PERF & 10 & 10 & 0 & & 100.00 \\
\hline V.COP.ROOT & 20 & 20 & 0 & & 100.00 \\
\hline V.COP.TENS.PRES & 110 & 57 & 53 & V.COP.PRES, V.LIGHT.TENS.PRES, VAUX.TENS.PRES & 51.82 \\
\hline V.INF & 10 & 10 & 0 & & 100.00 \\
\hline V.LIGHT.IMPERF & 40 & 37 & 3 & V.LIGHTV.IMPERF & 92.50 \\
\hline V.LIGHT.KER & 50 & 21 & 29 & V.LIGHT.ROOT & 42.00 \\
\hline V.LIGHT.PERF & 40 & 36 & 4 & V.LIGHTV.PERF, V.PERF & 90.00 \\
\hline V.LIGHT.ROOT & 30 & 30 & 0 & & 100.00 \\
\hline V.LIGHT.TB.ROOT & 30 & 13 & 17 & V.LIGHT.ROOT & 43.33 \\
\hline V.LIGHTV.PERF & 60 & 54 & 6 & V.LIGHT.PERF & 90.00 \\
\hline V.LIGHTV.PROG.IMPERF & 10 & 5 & 5 & V.LIGHTV.IMPERF & 50.00 \\
\hline V.PERF & 200 & 189 & 11 & VAUX.PASS.PERF & 94.50 \\
\hline V.ROOT & 20 & 20 & 0 & & 100.00 \\
\hline V.TENS.PRES & 50 & 21 & 29 & V.PRES & 42.00 \\
\hline VAUX.IMPERF & 20 & 17 & 3 & V.PASS.IMPERF & 85.00 \\
\hline VAUX.LIGHTV.TENS.PRES & 10 & 4 & 6 & VAUX.PRES & 40.00 \\
\hline VAUX.MOD.PERF & 30 & 30 & 0 & & 100.00 \\
\hline VAUX.PASS.PERF & 40 & 40 & 0 & & 100.00 \\
\hline VAUX.PROG.PERF & 20 & 9 & 11 & VAUX.PROG, V.COP.PERF & 45.00 \\
\hline VAUX.TENS.FUTR & 20 & 10 & 10 & VAUX.FUTR & 50.00 \\
\hline VAUX.TENS.PAST & 10 & 3 & 7 & VAUX.PAST & 30.00 \\
\hline VAUX.TENS.PRES & 220 & 101 & 119 & VAUX.PRES & 45.91 \\
\hline
\end{tabular}

Figure 5: Annotators SSP tags distribution and confusion 
The format of data evaluation in the Krippendorf's $\alpha$ was different from the data displayed in Figure 5, however, a sample of annotators' SSP tags distribution and confusion is displayed in Figure 5 . The annotated data of 100 sentences that were given to the annotators contained 1281 tokens, from which the data of 904 tokens is presented. The rest of the tokens have accuracy almost more than $90 \%$ due to which they are not depicted. It is attempted to show the tags of those tokens on which the annotators were remained confused or disagreed. The tags used in the initial version of the URDU.KON-TB treebank are displayed in the first column of the figure. Adjective (ADJ) appeared 54 times in the sentences, which were then annotated by 5 annotators. The frequency of adjective annotation is depicted in the second column of the figure after multiplying 54 with 5 numbers of annotators. It concludes 270 times of annotation for adjective. Among the 270 annotations of ADJ, annotators were remained 265 times in agreement or the annotators assigned 265 times the same/identical tag ADJ. The number of times the annotators remained disagreed or confused is mentioned in the different column. Similarly, the different or confused or the disagreed tags used by the annotators are depicted in the next column. Finally, by dividing the values in the identical and the frequency columns, the percentage accuracy of each tag in the first column of the figure is calculated.

The SSP tags in the initial version of the URDU.KON-TB treebank, which are correctly annotated and have $100 \%$ accuracy include ADV and ADV with its semantic labels for adverbs, coordination conjunctions with C.CORD, case markers with CM, N.PROP, N.PROP.SPT and N.TMP for proper nouns, spatial proper nouns and temporal nouns, P.DEM and P.INDF for demonstrative and indefinite pronouns, etc. The tags contained less than or equal to $50 \%$ accuracy include tense auxiliaries e.g. VAUX.TENS.PRES mostly annotated differently with VAUX.PRES, progressive auxiliary e.g. VAUX.PROG.PERF annotated differently with VAUX.PROG and its copular behavior with V.COP.PERF, KER as a light verb e.g. V.LIGHT.KER annotated with V.LIGHT.ROOT, diacritics e.g. DIA.IZF with DIA only, etc. Annotation of some tokens with tags was left by the annotators represented with BLANK in the column 'different/confused/ disagreed tags' for each tag in the first column of the figure.

The error analysis and evaluation of tags was performed on the basis of this data depicted in Figure 5. First, the tags with less or equal to $50 \%$ of accuracy are revised with annotators decisions e.g. DATE.Y.CAL, PT.INTF, V.LIGHT.TB.ROOT, etc., and second are the tags with accuracy a little more than $50 \%$ but they have common confused pairs like V.COP.TENS.PRES and VAUX.TENS.PRES modified to V.COP.PRES and VAUX.PRES, respectively as can be seen in Figure 1. The detailed discussion on error analysis and evaluation of the SSP annotation is presented in (Abbas, 2014b). 


\section{Conclusion}

This concludes the complete SSP guidelines of the URDU.KON-TB treebank with preliminary and essential additional information needed to explain the SSP annotation procedure in full. After introducing the URDU.KON-TB treebank (Abbas, 2012; Abbas, 2014a; Abbas 2014b) and the parser based on the URDU.KON-TB treebank (Abbas, $2014 \mathrm{c} / 2015$ ), the demand of the complete guidelines in the community was raising, due to which it is attempted to present the SSP complete guidelines as a first step. The rest of the guidelines for the semi-semantic syntactic and functional annotations will be presented soon. This effort does not only strengthen the practice of producing the guidelines for the annotation schemes but also addresses the modern issue of how to prepare and evaluate guidelines (Mikulova and Stepanek, 2010) effectively with the state of the art evaluation techniques (Krippendorf, 2004; Hayes and Krippendorf, 2007). Corpus annotated with these SSP annotation guidline can be useful to applications in this domain like natural language processing, machine learning and many language specific analysis as discussed in ( Zia, et. al, 2015a/2015b; Abbas, et. al, 2009/2010/2014; Abbas 2014d).

\section{References}

Aarts, B., Chalker, S., \& Weiner, E. (2014). The Oxford Dictionary Of English Grammar. Oxford University Press.

Abbas, Q. (2012, March). Building a hierarchical annotated corpus of urdu: the URDU. KON-TB treebank. In International Conference on Intelligent Text Processing and Computational Linguistics (pp. 66-79). Springer Berlin Heidelberg.

Abbas, Q. (2014a). Semi-semantic part of speech annotation and evaluation. LAW VIII, 75.

Abbas, Q. (2014b). Building Computational Resources: The URDU. KON-TB Treebank and the Urdu Parser (Doctoral dissertation).

Abbas, Q. (2014c). Exploiting language variants via grammar parsing having morphologically rich information. LT4CloseLang 2014, 36.

Abbas, Q. (2014d). A Stochastic Prediction Interface for Urdu. International Journal of Intelligent Systems and Applications, 7(1), 94.

Abbas, Q. (2015). Morphologically rich Urdu grammar parsing using Earley algorithm, Natural Language Engineering (NLE), Vol.21(2), PP.1-36, Cambridge University Press, UK

Abbas, Q., \& Khan, A. N. (2009). Lexical functional grammar for Urdu modal verbs. In Emerging Technologies, 2009. ICET 2009. International Conference on (pp. 7-12). IEEE.

Abbas, Q., \& Raza, G. (2014). A Computational Classification of Dynamic Urdu Copula Verb. International Journal of Computer Applications, 85(10).

Abbas, Q., Ahmed, M. S., \& Niazi, S. (2010). Language Identifier For Languages Of Pakistan Including Arabic And Persian. International Journal of Computational Linguistics (IJCL), 1(03), 27-35. 
Abbas, Q., Karamat, N., \& Niazi, S. (2009). Development of Tree-bank based probabilistic grammar for Urdu Language. International Journal of Electrical \& Computer Science, 9(09), 231-235.

Abbas, Q., Zia, T., \& Khan, A. N. (2014). Syntactic and semantic analysis of Urdu modal verbs using XLE parser. International Journal of Computer Applications, 107(10).

Abbi, A. (1992). Reduplication in South Asian Languages: An Areal, Typological, And Historical Study. Allied Publishers, New Delhi.

Ahmed, T., \& Butt, M. (2011, January). Discovering semantic classes for Urdu NV complex predicates. In Proceedings of the Ninth International Conference on Computational Semantics (pp. 305-309). Association for Computational Linguistics.

Bhatt, R., Bögel, T., Butt, M., Hautli, A., Sulger, S., \& King, T. H. (2011). Urdu/Hindi modals. Bibliothek der Universität Konstanz.

Bögel, T., Butt, M., Hautli, A., \& Sulger, S. (2007). Developing a finite-state morphological analyzer for Urdu and Hindi. Finite State Methods and Natural Language Processing, 86.

Butt, M. (1995). The structure of complex predicates in Urdu. Center for the Study of Language (CSLI).

Butt, M. (2003). The light verb jungle [OL].

Butt, M. (2010). The light verb jungle: Still hacking away. Complex predicates in cross-linguistic perspective, 48-78.

Butt, M., \& King, T. H. (2004). The status of case. In Clause structure in South Asian languages (pp. 153-198). Springer Netherlands.

Butt, M., \& Ramchand, G. (2001). Complex aspectual structure in Hindi/Urdu. M. Liakata, B. Jensen, \& D. Maillat, Eds, 1-30.

Butt, M., \& Rizvi, J. (2010). Tense and aspect in Urdu. Layers of aspect, 43-66. Stanford: CSLI Publications.

Butt, M., \& Sadler, L. (2003). Verbal morphology and agreement in Urdu. Syntactic structures and morphological information. Mouton, 57-100.

Clark, A., Fox, C., \& Lappin, S. (2010). The Handbook Of Computational Linguistics And Natural Language Processing, 57. Wiley.com.

Facchinetti, R., Palmer, F., \& Krug, M. (Eds.). (2003). Modality in contemporary English (Vol. 44). Walter de Gruyter.

Hayes, A. F., \& Krippendorf, K. (2007). Answering The Call For A Standard Reliability Measure For Coding Data. Communication Methods and Measures, 1(1), 77-89.

Hirsch, E. D., Kett, J. F., \& Trefil, J. S. (2014). The new dictionary of cultural literacy. Houghton Mifflin Harcourt.

ljaz, M., \& Hussain, S. (2007, August). Corpus based Urdu lexicon development. In the Proceedings of Conference on Language Technology (CLTO7), University of Peshawar, Pakistan (Vol. 73).

Kamran Malik, M., Ahmed, T., Sulger, S., Bögel, T., Gulzar, A., Raza, G., ... \& Butt, M. (2010). Transliterating Urdu for a Broad-Coverage Urdu/Hindi LFG Grammar. In LREC 2010, Seventh International Conference on Language Resources and Evaluation (pp. 29212927). 
Krippendorff, K. (2004). Reliability in content analysis. Human communication research, 30(3), 411-433.

Leech, G. (2005). Adding linguistic annotation. , 17-29, Oxbow Books, Oxford.

Matthews, P. H. (2007). The concise Oxford dictionary of linguistics. Oxford University Press.

Mikulova, M., \& Stepanek, J. (2010). Ways Of Evaluation Of The Annotators In Building The Prague Czech-English Dependency Treebank. In LREC.

Miller, G. A., Beckwith, R., Fellbaum, C., Gross, D., \& Miller, K. J. (1990). Introduction to WordNet: An on-line lexical database. International journal of lexicography, 3(4), 235 244.

Mohanan, T. (1994). Argument structure in Hindi. Center for the Study of Language (CSLI).

Raza, G. (2010). Inferring Subcat Frames of Verbs in Urdu. In LREC.

Raza, G. (2011). Subcategorization acquisition and classes of predication in Urdu (Doctoral dissertation).

Schmidt, R. L. (2013). Urdu, an Essential Grammar. Psychology Press.

Skut, W., Krenn, B., Brants, T., \& Uszkoreit, H. (1997, March). An annotation scheme for free word order languages. In Proceedings of the fifth conference on Applied natural language processing (pp. 88-95). Association for Computational Linguistics.

Stevenson, A. (Ed.). (2010). Oxford dictionary of English. Oxford University Press, USA.

Urooj, S., Hussain, S., Adeeba, F., Jabeen, F., \& Parveen, R. (2012). CLE Urdu digest corpus. LANGUAGE \& TECHNOLOGY, 47.

Zia, T, Akhtar, M. P., Abbas, Q. (2015a). Comparative Study of Feature Selection Approaches for Urdu Text Categorization. Malaysian Journal of Computer Science, 28(2).

Zia, T., Abbas, Q., \& Akhtar, M. P. (2015b). Evaluation of Feature Selection Approaches for Urdu Text Categorization. International Journal of Intelligent Systems and Applications, 7(6), 33. 